\title{
5 Der Existentialismus als Subkultur
}

Nun ist ziemlich undenkbar, daß etwa Bergson Lieder für die Mistinguette geschrieben hätte oder daß Max Scheler einem Gasthaus gestattet hätte, seinen Namen als unsichtbares Aushängeschild zu benutzen!

Hanns Mayer, „Metaphysik und Bee-Bop“.

\subsection{Mode und mode de vie: Von St. Germain-des-Prés zum „Strohkoffer“}

Der „Mensch als Inbegriff seiner Möglichkeiten“"1, dem allein die Verantwortung für sein Tun obliegt, entspricht nach Ende des Zweiten Weltkriegs nicht nur in Frankreich den auf Neuanfang stehenden Zeichen der Zeit, sondern, so Karl Jaspers 1951 in der Schweizer Illustrierten, auch „in der breiten Welt“, jedoch: „Ohne Sartre wäre die Sache auf engere Kreise beschränkt geblieben. Sie machte als Mode erst von sich reden, als der Dichter sie vertrat und in seinem dichterischen Werk ihr Sprache gab.“2 Bevor sich weite Teile dieses Werks in Übersetzungen zwischen den Kulturen vermitteln lassen, passiert bereits der mit dem Existentialismus verbundene Sprach-, Kleidungs- und Lebensstil die Grenzen.

Durch Periodika transferierte Schlüsselwörter wie „Entscheidung“, „Sinnlosigkeit“, „Freiheit“, „Verantwortung“ greifen bald genügend auf den allgemeinen Sprachgebrauch über, um den Kern zahlreicher Parodien zu bilden (cf. Kap. 8.2). Der Grundtenor lässt sich an Erich Kästners Miniatur „Ist Existentialismus heilbar?" ablesen, deren Ich sich einige Tage mit existentialistischen Büchern in ein Gebirgstal zurückzieht, um das allgegenwärtige „Donnerwort“ mit Inhalt zu füllen, im Zustand fortgeschrittener Verwirrung jedoch nur Rettung findet im Satz: „,Im Grunde hat das Wort Existentialismus heute einen solchen Umfang und eine solche Ausdehnung angenommen, daß es überhaupt nichts mehr bedeutet!“‘3 Kästner zitiert hier eine Aussage aus Sartres Ist der Existentialismus ein Humanismus?, die lautet, ,im Grunde hat das Wort heute einen solchen Umfang und eine solche Ausdehnung angenommen, daß es überhaupt nichts mehr bedeutet“4. Der Begriff bezeichnet zu Sartres und Beauvoirs Leidwesen nicht nur eine uneinheitliche Gruppe

1 Robert Musil: Der Mann ohne Eigenschaften. Hg. von Adolf Frisé. Reinbek 2014, S. 251.

2 Karl Jaspers: Was ist Existentialismus? In: Jaspers: Aneignung und Polemik. Gesammelte Reden und Aufsätze zur Geschichte der Philosophie. Hg. von Hans Saner. München 1968, S. 497-501, hier S. 497. [Zuerst in: Schweizer Illustrierte 40 (1951), Nr. 18.]

3 Erich Kästner: Ist Existentialismus heilbar? In: Kästner: Die kleine Freiheit. Chansons und Prosa 1949-1952. München 1989, S. 67, 71f.

4 Jean-Paul Sartre: Ist der Existentialismus ein Humanismus? Zürich 1947, S. 10.

Ә Open Access. ( 2021 Juliane Werner, publiziert von Walter de Gruyter. (c) BY lizensiert unter einer Creative Commons Namensnennung 4.0 International Lizenz. https://doi.org/10.1515/9783110683066-005 
von Intellektuellen, SchriftstellerInnen und PhilosophInnen, sondern auch in Saint-Germain-des-Prés aktive MalerInnen, MusikerInnen und SchauspielerInnen. So ist der Existentialismus am ehesten durch seine Lokalisierung greifbar, als ein diffuses soziokulturelles Phänomen des 6. Pariser Arrondissements. ${ }^{5}$ Jener am linken Seine-Ufer gelegene Ballungsraum von Fakultäten, Buchhandlungen, Verlagen, Theatern, Clubs und Kaffeehäusern kann 1949 in Österreich als hinlänglich bekannt vorausgesetzt werden, wie folgender Auszug aus Kulturelles zeigt:

Am Boulevard St. Germain wohnen, wie jedermann von Timbuktu bis Amstetten weiß, die Existentialisten. Tatsächlich wohnen auch andere, Schriftsteller und Maler, Philosophen und Traktätchenfabrikanten dort, aber sie stehen hinter dem größeren Ruhm der Existentialisten zurück. Manche Leute behaupten, Jean Paul Sartre sei ein Mythos, keine wirkliche Persönlichkeit, vom Fremdenverkehrsverein und der Buchzentrale zur Überbrückung der Krise erfunden. ${ }^{6}$

In der Tat ist Sartre dank seiner „profound aversion to privacy, secrecy, to the bad faith of concealment, inhibition, masquerading, and posturing ${ }^{\text {“7 }}$ und dem damit einhergehenden Wunsch, so lange wie möglich in der Öffentlichkeit zu arbeiten, als Sehenswürdigkeit so weit touristisch erschlossen, dass amerikanische ReiseleiterInnen gesondert auf ihn hinweisen. Nachdem der Existentialismus - nicht anders als „in der Schweiz, Italien, Schweden und England“ - in den Vereinigten Staaten „einen immer größeren Zulauf“ erhält, wird der „freundliche und weich veranlagte Sartre“ auch in den Presse-Schilderungen der amerikanischen Streitkräfte in Österreich ins Zentrum „der fröhlichen Geselligkeit des Café Flore, wo langmähnige Künstler, Schriftsteller, Universitätsprofessoren und Filmdirektoren bei ihrem Fünf-Uhr-Aperitif ihre intellektuelle Konversation pflegen“8, gestellt. Das „Café de Flore“ und das „Deux Magots“ verkörpern nicht weniger als „Kreuzungspunkte Europas und der Welt“: „Amerikanische Schriftsteller kommen und gehen, ein englischer Philosoph plaudert

5 Cf. Jacques Dugast: La Situation culturelle de la France après 1945. In: Eßbach (Hg.): Welche Modernität?, S. 305-316, hier S. 309.

6 o. V.: La Rive Gauche / Pariser Feuilleton. In: Kulturelles, 12.09.1949.

7 Eduardo Mendieta: The City and the Philosopher: On the Urbanism of Phenomenology. In: Philosophy \& Geography 4 (2001), Nr. 2, S. 203-218, hier S. 208. Sartre bleibt, erinnert sich Manès Sperber, auch in der Öffentlichkeit „in Sprache und Gebärde von jeder Pose frei“: „Im persönlichen Verkehr erwies sich Sartre als überaus freundlich, ja herzlich [...]. Sein Erfolg war ihm nicht zu Kopf gestiegen, seine Umgangsformen änderten sich auch später nicht, als er in der ganzen Welt so berühmt wurde, daß Intellektuelle und fortschrittliche Bürger sich in allen Dingen nach ihm zu richten begannen.“ Manès Sperber: Nur eine Brücke zwischen Gestern und Morgen. München 1983 [1980], S. 40.

8 UP.: Philosophie der Verantwortung und Moral. Sartre und die Grundgedanken des Existenzialismus. In: Wiener Kurier, 05.12.1946. 
mit einem französischen Kollegen, Bücher aus Rom und aus Moskau, Zeitungen aus London und New York, Manuskripte aus allen Gegenden türmen sich auf den Tischen"9, berichtet der französische Schriftsteller und Journalist Claude Roy 1946 für den amerikanischen Wiener Kurier, welcher wiederholt auf KulturredakteurInnen der französischen Besatzungsmacht zurückgreift. ${ }^{10} 1951$ wird der Existentialismus im österreichischen Besatzungs-Bulletin Geistiges Frankreich als gewaltige Marketing-Leistung präsentiert:

Heute haben Jean-Paul Sartre und die jungen Leute, die ihm teils wirklich, teils angeblich ihren Lebensstil verdanken, allen diesen Stätten neuen Ruhm verschafft. Wir wollen hier nicht viel davon erzählen, es ist schon genug darüber geschrieben worden, ein Kritiker nannte die Existentialisten von St. Germain sogar den grössten Reklameerfolg seit dem Zirkus Barnum. Heute gehören die unterirdischen Nachtlokale mit ihren New OrleansJazz-Orchestern und ihren ausgezeichneten Kabaretts, die schwarz gekleideten Mädchen und die Jungen in bunten Hemden, denen Lebensangst und Lebensgier aus den Augen schauen (und wer möchte ihnen heute einen Vorwurf daraus machen?), gehören alle diese Wahrzeichen des Nachkriegs-Paris ebenso zu Saint-Germain-des-Prés, wie Antiquare und Buchbinder, die auch dieser Erscheinung stand zu halten verstehen. ${ }^{11}$

Nicht lang nach diesem Bericht erschafft die im burgenländischen Mattersburg aufgewachsene Jungautorin Hertha Kräftner eine nicht unähnliche Momentaufnahme vom Rive Gauche-Treiben. Sie hat zu diesem Zeitpunkt bereits Sartre gelesen, „most of his works“"12, wie ein Brief an ihre Freundin Marguerite Rebois vom 2. November 1950 verrät. In Kräftners im „Pariser Tagebuch“ festgehaltenen Impressionen, die ihr 1951 den 1. Prosapreis der Zeitschrift neue wege einbringen, steht das äußere Erscheinungsbild der ExistentialistInnen klar im Vordergrund:

$\mathrm{Zu}$ St. Germain-des-Prés gehört, wer keine Strümpfe trägt in seinen Strohsandalen; wer seine langen Haare kräuselt, wo sie den offenen Kragen des schwarzen Hemdes erreichen; wer niemals seinen Samtrock bürstet; wer lange Hosen unter Kleidern trägt und seine Haare schneidet, kurz und wild, falls er ein Mädchen ist. ${ }^{13}$

9 Claude Roy: Kellner ... etwas zum Schreiben! In: Wiener Kurier, 12.01.1946.

10 Zutreffend etwa auch auf den nach 1945 bei den französischen Radiostationen Dornbirn, Innsbruck und Wien eingesetzten Jean Prieur (1914-2016), der im Wiener Kurier in der Rubrik „Neue französische Bücher“ am 19.02.1946 Camus' Lettres à un ami allemand (1945) und Sartres Les Chemins de la liberté vorstellt.

11 o. V.: Saint-Germain-des-Prés. In: Geistiges Frankreich, 19.03.1951.

12 Hertha Kräftner: Kühle Sterne. Gedichte, Prosa, Briefe. Aus dem Nachlass hg. von Gerhard Altmann und Max Blaeulich. Frankfurt am Main 2001, S. 226.

13 Hertha Kräftner: Aus dem Pariser Tagebuch 1950. In: neue wege 6 (1950), Nr. 60, S. 120121, hier S. 120. 
Schon im Einleitungssatz artikuliert sich laut Sabine Scholl „die Nichtzugehörigkeit der Beobachterin“14, die in weiterer Folge Kritik an der Oberflächlichkeit der Existentialismus-AdeptInnen übt, denen der eigentliche philosophische Gehalt unverständlich bleibt:

Im Café des deux Magots gingen zwei herum, singend ohne Melodie und Gitarre spielend, wie wenn ein Fleischer Kühe tötet. Und die Fremden zahlten, dankbar und entzückt. Im Café de Flore daneben sitzt Sartre manchesmal, und sie verehren ihn wie einen Gott aus fremden Ländern. Sie leben seine Bücher, die sie nicht verstehen. Sie tanzen und trinken sich zu Tod. Sie hungern, aber sie sind frei. Sie ekeln sich vor etwas, das sie nie begreifen. Am „Boul-Mich“ treiben sie auf und ab, Nachmittage lang; sie haben nichts zu tun. Sie fürchten sich vor einem Ende und ersticken sich. ${ }^{15}$

Das exzessive Trinken und Tanzen gehört zu einem Verhaltensspektrum, das das unmoralische Image des Existentialismus weithin befördert; so zieht Han[n]s Mayer zufolge der Sartresche „Geistesnebel“ bis in die USA, wo man die CollegeJugend sagen hört: „,Vater erzählt immer Mutter, er sei abends bei geschäftlichen Sitzungen. Dabei kam er gestern heim und roch nach Whisky wie ein Existentialist ... ‘ " ${ }^{16}$ Mayers Anekdote lässt an eine Bemerkung Sartres aus Ist der Existentialismus ein Humanismus? denken:

Kürzlich erzählte man mir von einer Dame, die, als sie aus Nervosität ein vulgäres Wort fallen ließ, sich entschuldigte: Ich glaube, ich werde Existentialistin. Demnach wird Häßlichkeit dem Existentialismus gleichgeachtet; und darum erklärt man uns für „Naturalisten“; und wenn wir es sind, kann man sich doch wundern, daß wir weit mehr Schrecken und Ärgernis erregen, als es der eigentliche Naturalismus heute tut. Jemand, der ohne weiteres einen Roman von Zola wie „La Terre“ schluckt, ist angeekelt, sobald er einen existentialistischen Roman liest; derselbe, der die Lebensweisheit der Völker - die höchst traurig ist - für sich anwendet, findet uns noch trauriger. [...] Man soll nicht gegen die etablierten Mächte kämpfen, man soll nicht gegen den Strom schwimmen, man soll nicht über seine Stellung hinaustrachten, jede Handlung, die sich nicht einer Überlieferung einfügt, ist Romantik ${ }^{17}$.

(Une dame dont on m'a parlé récemment, lorsque par nervosité, elle lâche un mot vulgaire, déclare en s'excusant: „Je crois que je deviens existentialiste.“ Par conséquent, on assimile laideur à existentialisme; c'est pourquoi on déclare que nous sommes naturalistes; et si nous le sommes, on peut s'étonner que nous effrayions, que nous scandalisions beaucoup plus que le naturalisme proprement dit n'effraye et n'indigne aujourd'hui. Tel qui encaisse parfaitement un roman de Zola, comme La Terre, est écœuré dès qu'il lit un

14 Sabine Scholl: Sex, Gott und Alkohol - Hertha Kräftners „Pariser Tagebuch“. In: Polt-Heinzl (Hg.): „Zum Dichten gehört Beschränkung“. Hertha Kräftner - ein literarischer Kosmos im Kontext der frühen Nachkriegszeit. Wien 2004, S. 122.

15 Scholl: Sex, Gott und Alkohol, S. $120 \mathrm{f}$.

16 Hanns Mayer: Metaphysik und Bee-Bop. In: Die Zeit, 17.05.1951.

17 Sartre: Ist der Existentialismus ein Humanismus?, S. 7 ff. (Hervorhebung im Original). 
roman existentialiste; tel qui utilise la sagesse des nations - qui est fort triste - nous trouve plus triste encore. [...] il ne faut pas lutter contre les pouvoirs établis, il ne faut pas lutter contre la force, il ne faut pas entreprendre au-dessus de sa condition, toute action qui ne s'insère pas dans une tradition est un romantisme $)^{18}$.

Die hier wiedergegebene Passage aus Ist der Existentialismus ein Humanismus? findet sich 1955 gestrafft und frei ergänzt in der österreichischen Tageszeitung Die Presse, die aus Sartres Aussagen einen Dialog zwischen einem ,Bürgerlichen' und einem ,Existentialisten' kreiert:

,Sie sind ein Existentialist.

,So? Sie meinen wohl, ich rede vulgär oder wäre vulgär. Sie setzen also das Vulgäre und den Existentialismus gleich. Dann wäre ich ein Naturalist ... ‘

Der ,Bürgerliche“ brach daraufhin die Unterhaltung ab. Was würde Monsieur Sartre darauf sagen? , ... und wenn wir Naturalisten sind, dann kann man sich nur wundern, daß wir wesentlich mehr abstoßen und peinlich berühren, als es der eigentliche Naturalismus tut. Jemand, der die Weisheit der Völker kennt - die recht traurig ist - , findet uns noch trauriger. Jede Handlung, die sich nicht in eine Tradition einfügt, ist Romantik ... ‘ - Die Existentialisten fügen sich in keine Tradition ein: sind sie also Romantiker? ${ }^{19}$

Österreichische RedakteurInnen, die den Existentialismus nicht selten als „Schlagwort [...], mit dem in den Revuen Fangball gespielt wird“20, aufgreifen analog zu Kästners vielfältig einsetzbarem „Donnerwort“ - ziehen insbesondere Ist der Existentialismus ein Humanismus? als Fundus heran. Neben dem charakteristischen Duktus des Existentialismus werden als integrale Aspekte Kleidung und Gesichtsbehaarung der von ihm Betroffenen vorgeführt:

Jene, die auf jeden Fall dagegen sind, bewitzeln die Bärte, die noch manche der Jünger tragen. Einer dieser Bärtigen meinte auf eine diesbezügliche bissige Bemerkung eines ,Bürgerlichen': ,Sie stört es, weil ich einen Backenbart trage? Was hätten Sie vor vierzehn Tagen gesagt, da hatte ich noch einen Vollbart! Und einen Monat vorher einen Schnurrbart ... ‘

,Sie glauben wohl, auf diese Weise recht originell zu wirken, wie?‘

,Möglich, eines jedoch auf jeden Fall: ich führe das Barttragen an sich ad absurdum. Finden Sie das nicht auch? - Einmal Backe, einmal Oberlippe, absurd, was?

,Sie sind ein Existentialist. ${ }^{21}$

Noch 1954 kommt man im Boulevardblatt Bild-Telegraf auf die in gewissen Wiener Kreisen verbreitete „merkwürdige Haar- und Barttracht“ zu sprechen, richtigstellend, dass diese ,vor vielen Jahren in Paris en vogue war und als modern-existentialistisch galt, hier in Wien aber unter einem dichten Filz oft

18 Sartre: L’Existentialisme est un humanisme, S. $23 \mathrm{f}$.

19 Z.-F.: Wiener Existentialisten flüchten ins „Exil“. In: Die Presse, 22.01.1955.

20 S. F.: Besuch bei Jean-Paul Sartre. In: Die Presse, 12.07.1952.

21 Z.-F.: Wiener Existentialisten flüchten ins „Exil“. In: Die Presse, 22.01.1955. 
nur sehr, sehr junge Gesichter verschwinden läßt“‘22. Nicht Philosophie und Literatur stünden im Mittelpunkt für jeden, der „modern ist und sich dafür hält“, sondern „Schnürlsamt, Rollkragenpullover und Fischerhosen“23. Man stößt in Wien auf Varianten: „Solche mit Bärten und solche ohne. Einige in Schnürlsamthosen, die anderen in Blue-jeans. Mit Krawatten oder mit Mascherl. Mädchen in Korsarenhosen. Kinder von 30 und Männer von 17 Jahren. “24 Wenig Gehör finden Stimmen, die versuchen, den Existentialismus vor seinem oberflächlichen Ruf zu retten, zumal er schon in Frankreich, also vor jedem Transfer, vollkommen zweckentfremdet ist, so Jean Cocteau am 16. Juli 1951 in seinem Tagebuch:

Nie zuvor hat man ein Wort so weit von seiner ursprünglichen Bedeutung sich entfernen sehen. Nichts tun, in kleinen Kellerlokalen herumsitzen und trinken, das heißt Existenzialist sein. Das ist, als gäbe es in New York Relativisten, die in Kellerlokalen tanzen, und man stellte sich vor, Einstein tanze mit ihnen. Sartre ist an dem Phänomen völlig unschuldig. Es gibt keinen besser erzogenen, keinen unverdorbeneren, keinen hochherzigeren Menschen als ihn. Das Nichtstun ist ihm zuwider. Wir wundern uns oft gemeinsam über den seltsamen Weg, den seine Schule genommen hat. ${ }^{25}$

(Jamais on ne vit un terme s'éloigner davantage de ce qu'il exprime. Ne rien faire et boire dans des petites caves, c'est être existentialiste. C'est comme s'il existait à New York des relativistes qui dansent dans des caves et qu'on croie qu'Einstein y danse avec eux. Sartre est complètement irresponsable de ce phénomène. Il est l'homme le mieux élevé, le cœur le plus correct, l'âme la plus noble que je connaisse. Il déteste la fainéantise. Nous nous étonnons souvent ensemble de l'étrange chemin parcouru par son école.) ${ }^{26}$

Boris Vian weist in seinem bewusst kurz gehaltenen Sartre-Eintrag im Manuel de Saint-Germain-des-Prés (1951) darauf hin, seines Freundes Tätigkeit als Schriftsteller, Dramatiker und Philosoph stehe in keinerlei Zusammenhang mit Äußerlichkeiten (,rigoureusement aucun rapport avec les chemises à carreaux, les caves ou les cheveux longs“ ${ }^{\text {27 }}$ ). In Sartre, bestätigt Mayer, trifft man einen von allen modischen Entwicklungen unbeeindruckten, „kleinen unauffällig

22 L.: Bärte und Kunst sind im „Exil“. In: Bild-Telegraf, 09.12.1954.

23 L.: Bärte und Kunst sind im „Exil“. In: Bild-Telegraf, 09.12.1954.

24 Z.-F.: Wiener Existentialisten flüchten ins „Exil“. In: Die Presse, 22.01.1955. Cuno Fischer zeichnet in seinem Artikel „Existenzialisten“ für die deutsche Zeit vom 06.08.1953 folgendes Bild vom existentialistischen Look: „verwaschener Cord mit Fleckendessin, schwarze Strümpfe, die Stücke fischweißer Beine freilassen, Kettchen irgendwo, Hindenburgfrisur amerique“.

25 Jean Cocteau: Vollendete Vergangenheit. Band 1. Tagebücher 1951-1952. Hg. von Pierre Chanel, Deutsch von Frieda Grafe und Enno Patalas, mit einem Vorwort von Joachim Kaiser. München, Zürich 1989, S. 11.

26 Jean Cocteau: Le Passé défini. I. 1951-1952. Journal, texte établie et annoté par Pierre Chanel. Paris 1983, S. 11 (Hervorhebung im Original).

27 Vian: Manuel de Saint-Germain-des-Prés, S. 203. 
nach Beamtenart gekleideten Herrn“, während „Damen der Gesellschaft, wenn sie sich ein besonders kühnes Kleid machen lassen, von einer ,robe très existo“ sprechen“28. Die Mode der ExistentialistInnen ist „ein unerschöpfliches Thema der Pariser Tagesgespräche“, berichtet Rolf Italiaander 1949 den LeserInnen des deutschen Wochenblattes Die Zeit, die er sogleich aufklärt, dass sich das Existentialistische eines Mantels im „Vorhandensein nur eines einzigen Knopfes“ zeigt, und dass insbesondere auf Unterwäsche zu achten sei, da „der Existentialismus eine neue Lehre unseres Seelenlebens ist und da[ß] das Unterhemd und die Unterhose der Seele näher sitzen als andere Kleidungsstücke“،29. Ganz ohne Ironie berichtet in Österreich die vom französischen Pressedienst herausgegebene Europäische Rundschau 1949 unter der Überschrift „Die Tracht“ von den vestimentären Verpflichtungen der Gruppe:

Bei den Existenzialisten, in der Gegend von Saint-Germain-des-pres [!], ist seit ein paar Monaten das Tragen eines Regenmantels mit einer Kapuze modern geworden, dessen Knöpfe durch Holzstücke ersetzt sind. Sie stammen aus den alliierten Exzeßgütern, die seit Kriegsende zum Verkauf gelangten. Ihr Preis war ursprünglich $2400 \mathrm{fr}$. Francs, seit sie aber so in Mode gekommen sind, daß jeder Existenzialist und jede Existenzialistin, die etwas auf sich halten, einen solchen Mantel besitzen muß, wird für ein Exemplar - 7500 fr. Francs verlangt, und auch gegeben. ${ }^{30}$

Das Renommee als „Dior der Philosophie“311, das Sartre in Österreich bald innehat, wird die eigentliche philosophisch-literarische Strömung in Form eines Metaphernrepertoires überlagern, aus dem noch 1962 eine Theaterkritik Otto Basils schöpft:

Sartres Figuren sind philosophische Mannequins, die nach der Pfeife eines geistigen Modeschöpfers tanzen. Ob man also in der Existenzphilosophie einmal mehr gerafften Weltekel oder etwas Geworfensein (zu nihilistischen Fransen) trägt, [...] hängt im wesentlichen von den großen Modeschauen des Existenzialismus im „Deux Magots“ oder Saint Tropez ab. ${ }^{32}$

Das Äußere steht als visuell wahrnehmbarer Abgrenzungswille vom Bürgertum im Vordergrund der Berichterstattung über die Wiener ExistentialistInnentreffs. Was dabei stets mitschwingt, ist die Annahme, dass sich die Jugend ,in einer modernen Tracht genügte, ohne daß der Geist wirklich vorwärtsgerichtet

28 Mayer: Metaphysik und Bee-Bop. In: Die Zeit, 17.05.1951.

29 Rolf Italiaander: Die Mode der Existentialisten. In: Die Zeit, 07.04.1949.

30 o. V.: Aus Paris wird uns geschrieben ... In: Europäische Rundschau 4 (1949), Nr. 3, S. 25.

31 Wolfgang Kraus. In: Wolfgang Ritschl: Zur Freiheit verurteilt. Der Siegeszug des Existenzialismus. Ö1, 08.04.2005. http://oe1.orf.at/artikel/207083 (einges. 09.01.2019).

32 Otto Basil: Jean Paul Sartre, Die schmutzigen Hände, Theater in der Josefstadt. In: Basil: Lob und Tadel. Theaterkritiken 1947 bis 1966. Hg. vom Kollegium Wiener Dramaturgie. Wien, München 1981, S. 266-269, hier S. 267. [Zuerst in: Neues Österreich, 26.01.1962.] 
war“33, ein Vorbehalt vor allem auch aus wissenschaftlichem Blickwinkel (cf. Kap. 7.2) gegenüber denen, die

sich in einem bizarren Haarschnitt und in einer ausgefallenen Kleidung gefallen und ein verrücktes Geckentum an den Tag legen. Sartre hat sich durch öffentliche Maueranschläge von diesen seinen ,Verehrern' distanziert. Sie sind aber trotzdem echte Lehrjungen, die die Banknoten seiner Philosophie jetzt in Kleingeld verausgaben. Beweist nicht gerade ihr Geckentum ihre ,absolute Freiheit'? ${ }^{34}$

Es ist der als vulgär empfundene Lebens- und Kleidungsstil der AnhängerInnen, dem sich das Sensationspotential des ,Sartrismus' und damit die Aufmerksamkeit der breiteren Öffentlichkeit verdankt, in Wien wie in Paris. Simone de Beauvoir fürchtet die Konsequenzen, wenn sie fragt, welches Vertrauen man schon einer Philosophie entgegenbringen solle, die Orgien nach sich ziehe (,[q]uelle confiance accorder à un philosophe dont la doctrine inspire des orgies? Comment croire à la sincérité politique d'un ,maître à penser' dont les disciples ne vivent que pour s’amuser?“35). Auf die „unnütze Jugend“ stürzt sich in Österreich nicht nur die „Skandalpresse“36, sondern auch die bürgerliche, für die dieser Teil des Wiener Nachtlebens „keineswegs der langweiligste“ ist, kann man dort doch rechnen mit „Leuten, die prominent sind, belagert von Journalisten, die nach Sensationen oder zumindest nach Außergewöhnlichem suchen“37. Entsprechend lässt sich die Enttäuschung über unauffälliges Verhalten nicht verbergen, als der Bild-Telegraf am 9. Dezember 1954 einräumen muss: „Mit Sensationen über den ,Nachtbetrieb“ können wir diesmal leider nicht aufwarten.“38

Im Mittelpunkt der Wiener Szene steht das zum österreichischen „Art Club“ gehörende Lokal „Strohkoffer“39, wo jenem jazzuntermalten, verrauchten KellerAmbiente $\mathrm{zu}$ begegnen ist, das Beauvoir in ihrem allgemein als Schlüsselroman

33 L.: Bärte und Kunst sind im „Exil“. In: Bild-Telegraf, 09.12.1954.

34 Fischl: Idealismus, Realismus und Existentialismus der Gegenwart, S. 315.

35 Beauvoir: La Force des choses, Bd. 1, S. 200.

36 Günther Nenning: Sankt Sartre. Komödiant und Märtyrer, gestorben am 15. April 1980. In: FORVM 1980, Nr. 319-320 [Juli-August], S. 20-27, hier S. 22. Das verbreitete Gleichsetzen des Existentialismus mit Nichtstun liegt nahe in Anbetracht der Art, wie viele Blätter ihn vorstellen, so das Vorarlberger Volksblatt, eine Tageszeitung der Österreichischen Volkspartei: „Die neue, von J. P. Sartre vertretene philosophische Richtung des sogenannten Existenzialismus ist viel diskutiert. Diese philosophische Richtung stellt eine leichte, manchmal lockere Lebensauffassung dar, ein süßes ,Farniente‘ als Reaktion auf die schweren Jahre des Krieges.“ Dr. H. H.: Das Paris von 1947. In: Vorarlberger Volksblatt, 06.03.1947.

37 Z.-F.: Wiener Existentialisten flüchten ins „Exil“. In: Die Presse, 22.01.1955.

38 L.: Bärte und Kunst sind im „Exil“. In: Bild-Telegraf, 09.12.1954.

39 Cf. Maria Fialik: „Strohkoffer“-Gespräche. H. C. Artmann und die Literatur aus dem Keller. Wien 1998. 
aufgefassten Les Mandarins (1954) porträtiert („,[1]es petits zazous, le jazz, les caves qui puent le tabac et la sueur“40). Dieses Werk ist Beauvoirs einziges, das in der österreichischen Presse der Besatzungsjahre einen deutlichen Widerhall erfährt. Zuvor findet sie die längste Zeit lediglich als bekannteste „Schülerin des ,Papstes des Existentialismus““41, als „Jean-Paul Sartres Frau“42 oder bis zu einem gewissen Grad als Reiseschriftstellerin mit L'Amérique au jour le jour Erwähnung; ihr fundamentales Werk Le deuxième Sexe, das 1951 erstmals in deutscher Sprache erscheint, wird als pornographisch verworfen und ignoriert. ${ }^{43}$ Da sich die Begegnung mit Les Mandarins hauptsächlich 1956 vollzieht, kurz nach Sartres zweitem Skandal-Auftritt 1954 in Wien (cf. Kap. 8.2), findet der dadurch als prokommunistisch gelesene Roman vor allem durch seine Einblicke in das zügellose Intellektuellenleben in Pariser Kellern (mehrheitlich negative) Beachtung.

So wie sich das Pariser Geschehen hauptsächlich unterirdisch abspielt weshalb Vian in seinem Manuel de Saint-Germain-des-Prés die HauptakteurInnen als Dauerbewohner des Untergeschosses (,habitants permanents du soussol“), wenn nicht als Troglodyten (,troglodytes“44) bezeichnet - trifft sich auch die Wiener Avantgarde unter Grund: Der im Februar 1947 gegründete „Art Club“, nach Gerhard Rühm „sammelbecken aller - damals noch spärlichen fortschrittlichen künstlerischen tendenzen“" ${ }^{45}$, bekommt im Dezember 1951 in

40 Simone de Beauvoir: Les Mandarins. Paris 1954, S. 18. Cuno Fischer (Existenzialisten. In: Die Zeit, 06.08.1953) veranschaulicht das simple Erfolgsrezept: „Man kann Kellerkneipen zu begehrten Etablissements machen, wenn man es versteht. Ein Kneipenwirt verstand. Er ließ den Schwamm in Mauerrissen, ließ die Glühbirne ohne Milchglaskugel, ließ die Reste blumiger Tapeten hinter der Theke locker hängen, ließ sich nicht rasieren und trug schwarz konturierte Fingernägel. Irgendwie - dieses Wort ist dem Fluidum dienlich - hörte irgendwer davon. Und da kamen sie schon: Die, von denen die anderen sagen, ,das sind Existenzialisten'““

41 o. V.: Les Mains Sales [Schmutzige Hände] von Jean-Paul Sartre. In: Kulturelles, 26.04.1948.

42 Kauer: Die Mandarins von Paris. In: Volksstimme, 20.01.1955.

43 In der breiteren Öffentlichkeit als Feministin wahrgenommen wird Beauvoir ab den siebziger Jahren, insbesondere ab 1978, dem Jahr, in dem sie als erste Frau mit dem „Österreichischen Staatspreis für Europäische Literatur“ ausgezeichnet wird. Aus diesem Anlass wurde sie (zusammen mit dem zufällig anwesenden Sartre) von der Journalistin Krista Fleischmann in Paris interviewt - das lange Gespräch ist laut einer E-Mail-Auskunft Fleischmanns vom 27. August 2019 nicht archiviert worden -, 1979 folgt ein zweites Beauvoir-Interview von Trautl Brandstaller für ein ORF-Porträt.

44 Vian: Manuel de Saint-Germain-des-Prés, S. 42. [Übers. d. Verf.] Cf. dazu auch das Kapitel „Saint-Germain-des-Prés“ in Noël Arnauds Les Vies parallèles de Boris Vian (Paris 1970, S. 137-161).

45 Rühm: das phänomen „wiener gruppe“, S. 17. 
den Kellerräumlichkeiten unter der Loosschen Kärntner Bar (im Kärntner Durchgang 10, in der Inneren Stadt Wiens) ein Clublokal mit Galeriebetrieb zu Tageszeiten. Die vom Bildhauer Fritz Wotruba erdachte Bezeichnung „Strohkoffer“ geht zurück auf die geringe Größe und die mangels Tapeten mit Schilf ausgekleideten Wände. „Das Lokal war damals in Wien eine ausgesprochene Attraktion. Die Leute drängten sich wie die ominösen Sardinen in der Büchse“ ${ }^{\text {46 }}$, erinnert sich der Musiker Paul Kont; der Kunsthistoriker Alfred Schmeller betont, dass „der acht mal sechs Meter messende, rauchgeschwängerte ,Strohkoffer““47 diesem Ansturm nicht gewachsen war: „Jeden Abend war das Lokal, das für sechzig Leute zugelassen war, gerammelt voll. Bei manchen Veranstaltungen standen die Besucher auf der Stiege, bis hinauf auf die Straße.“48 Durch „einige turbulente feste“49 wird der Ort schnell zum „Zentrum für alle Jungen“50, zum „Anziehungspunkt eines vielfältigen Publikums, gemischt aus bärtigen Malern, Kabarettgrößen, kleinen Kunstgewerblerinnen, Hofräten, Stars von Bühne und Film, Journalisten, Industriellen und Aristokraten“"51. Die Diversität fördert ein Ineinanderübergehen der Künste, so Kont: „Künstler interessierten sich für Musikalisches, Musiker für Literatur, Schriftsteller für bildende Kunst. “52 Diese Wiener Symbiose erkennt die Tageszeitung Die Presse als einzigartig an:

Man sucht in Wien kein Vorbild, weil man sich selbst genügt - und weil man vernünftig ist. Es gibt nirgends sonst - auch im Ausland nicht - einen Klub, in dem alle Kunstrichtungen, sowohl die bildende als auch die Musik und die Literatur, aber auch die Graphik und die künstlerische Photographie, vertreten sind..$^{53}$

Der Vergleich mit Frankreich, dem europäischen „Nervenzentrum des Geistes“ ${ }^{\text {"54 }}$, liegt dennoch stets auf der Hand, so auch, als Ingeborg Bachmann Paul Celan von einem Club-Besuch im Februar 1952 schreibt: „Rund um uns war es ein bisschen wie Paris, und auch die Menschen sahen fast so aus wie die im

46 Paul Kont: Von der Musik her (1981). In: Breicha (Hg.): Der Art Club in Österreich, S. 46-47, hier S. 46.

47 Alfred Schmeller: Es rieselt im Gebälk des Art Clubs. In: Breicha (Hg.): Der Art Club in Österreich, S. 28-30, hier S. 30. [Zuerst in: Neuer Kurier, 24.05.1955.]

48 Alfred Schmeller: Ein Sammelsurium (1980). In: Breicha (Hg.): Der Art Club in Österreich, S. 31-34, hier S. 33.

49 Rühm: das phänomen „wiener gruppe“, S. 17.

50 Schmeller: Ein Sammelsurium, S. 33.

51 Schmeller: Es rieselt im Gebälk des Art Clubs, S. 30.

52 Kont: Von der Musik her, S. 47.

53 Z.-F.: Wiener Existentialisten flüchten ins „Exil“. In: Die Presse, 22.01.1955.

54 o. V.: Die französische Dichtung der Gegenwart. In: Weltpresse, 21.02.1946. 
Deux Magots.“55 Es handelt sich beim „Strohkoffer“ um ein Lokal, „das man in Paris eine boîte de nuit nennen würde“, stimmt „Art Club“-Präsident Albert Paris Gütersloh zu, für Wien sei es jedoch weit mehr, „eine Notwendigkeit dieser Stadt als Großstadt“, zugleich „eine entscheidende Attacke gegen die Flachlandsknechte der Provinz“ und damit, anders als in Paris, ein „Refugium der offiziell Verpönten und Geschmähten“"56. Deren Isolation spricht nach der Schließung des „Strohkoffer“ im Jahr 1953 aus dem Namen des sich im unweit gelegenen Nachfolgelokal Adebar (in der Annagasse 3, Innere Stadt) etablierenden Treffpunkts „Exil“, der „Programm, Bekenntnis und Vorwurf in einem, zugleich aber auch Koketterie mit dem eigenen Abseitsstehen“"57 ist. Die den französischen Avantgarde-KünstlerInnen in diesem Maß unbekannte Randlage im Kulturbetrieb fällt Jean Cocteau bei seinem Wien-Besuch im Mai 1952 auf; im Unterschied zum Pariser ExistentialistInnen-Milieu sei der „Art Club“ der Treffpunk einer finanziell und kulturell noch vollkommen mittellosen, isolierten Jugend (,le rendez-vous d'une jeunesse très pauvre, très fraîche et qui ne joue pas encore un rôle. Les jeunes artistes ne trouvent aucune réponse et se groupent pour se sentir moins seuls. Ils dessinent, ils peignent, ils écrivent, ils tissent avec des moyens

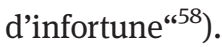

Gleich den Gästen der Pariser Hotspots (darunter Jean Genet, Raymond Queneau und Marguerite Duras, Boris Vian und Juliette Gréco, der Regisseur Alain Resnais sowie die Schauspieler Roger Blin und Daniel Gélin, aber auch

55 Ingeborg Bachmann: Herzzeit. Ingeborg Bachmann - Paul Celan. Der Briefwechsel, mit den Briefwechseln zwischen Paul Celan und Max Frisch sowie zwischen Ingeborg Bachmann und Gisèle Celan-Lestrange. Hg. und kommentiert von Bertrand Badiou, Hans Höller, Andrea Stoll und Barbara Wiedemann. Frankfurt am Main 2008, S. 44. Celans Verbindung zu Sartre beschränkt sich auf eine Unterstützungsbitte im Zuge der von Yvan Golls Witwe Claire Goll gegen ihn angestrengten Plagiatsaffäre. Celan bezeichnet diese in einem im Jänner 1962 geschriebenen, aber nicht abgeschickten Brief als „richtige Dreyfus-Affäre“ (,une vraie affaire Dreyfus“) und appelliert an Sartres „Gerechtigkeits- und Wahrheitssinn“ (,sens de la justice et de la véritéc): „Ich weiß natürlich, daß Sie Mühe haben, diesem Unbekannten zu glauben, der Ihnen schreibt. Erlauben Sie ihm, zu Ihnen zu kommen, um Ihnen, unterstützt durch die Dokumente, diesen Fall (von dem ich Sie bitte, mir zu glauben, daß er einzigartig ist) darzustellen.“ (,Je sais bien que vous avez du mal à croire cet inconnu qui vous écrit. Permettez-lui de venir vous exposer, avec les documents à l'appui, ce cas [dont je vous prie de croire qu'il est unique.]“) Paul Celan. In: Wiedemann (Hg.): Paul Celan - Die Goll-Affäre. Dokumente zu einer „Infamie“. Frankfurt am Main 2000, S. $544 \mathrm{f}$.

56 Albert Paris Gütersloh: Bedenken Sie doch die Zeit, in der wir leben. Rede vom 15.12.1951 zur Eröffnung der neuen Art Club-Galerie im „Strohkoffer“. In: Breicha (Hg.): Der Art Club in Österreich, S. 14-15, hier S. 14, 15.

57 L.: Bärte und Kunst sind im „Exil““. In: Bild-Telegraf, 09.12.1954.

58 Cocteau: Le Passé défini, S. 199. 
ältere wie André Breton, Jacques Prévert und die Künstler Alberto Giacometti, Georges Braque und Pablo Picasso) haben viele der BesucherInnen des Wiener „Strohkoffer“ (wie Friederike Mayröcker, Paul Blaha, Ernst Jandl, Konrad Bayer, Helmut Qualtinger, Andreas Okopenko, H. C. Artmann, Hanns Weissenborn, Gerhard Fritsch, Oswald Wiener, der Filmemacher Ferry Radax, der Musiker Friedrich Gulda, die MalerInnen und BildhauerInnen Maria Biljan-Bilger, Maria Lassnig, Rudolf Hausner, Friedensreich Hundertwasser, Ernst Fuchs und Arik Brauer) wenig mit dem existentialistischen Denken zu tun. Bei einigen, hervorzuheben sind Radax, ${ }^{59}$ Okopenko und Blaha, findet eine tiefergehende Auseinandersetzung mit Sartres Werken statt. Als selbsternannter Existentialist und noch in den 1990er Jahren existentialistischer Schriftsteller ${ }^{60}$ kommentiert Paul Blaha den „Strohkoffer“ wie folgt:

Da sind wir zu Beginn meiner Wien-Zeit jeden Abend gesessen, von sechs bis sechs. Geschlafen haben wir damals wenig. Der H.C. Artmann war genauso dort wie der Gulda, der Weigel, der Torberg und der Qualtinger. Die Diskussionen über Kunst, Kultur, Literatur und das Theater waren endlos. Das war eine wichtige Zeit. Nicht nur für mich. Im Strohkoffer war damals diese Nachkriegeskulturriege, wie man heute sagt. Das war auch eine wichtige Zeit für die Kulturszene Wiens. ${ }^{61}$

Blaha, Redakteur beim Bild-Telegraf, Theaterkritiker beim Kurier und von 1979 bis 1987 Direktor des für die Existentialismus-Rezeption in Österreich wichtigen Volkstheaters (cf. Kap. 8), gehört zu den wenigen, die einen persönlichen Eindruck von Sartre einfangen und wiedergeben:

Er war imponierend, ruhig, still und durchdringend. Er hatte immer etwas Forderndes, auch wenn er einen angesehen hat durch diese dicken Brillen. Man hat immer das Gefühl gehabt,

59 Ferry Radax' diesbezügliche Auskünfte, etwa in einem Interview mit Josef Schweikhardt (Mit nichts als Fantasie erschufen wir unsere Welt aus dem Nichts, S. 53), bleiben eher kryptisch: „Jean-Paul Sartre und Albert Camus ließen mich mein Schicksal wie vom Räderwerk einer gigantischen Bahnstation gelenkt erscheinen." http://www.ferryradax.at/film/film.htm (einges. 09.01.2019).

60 Erkennbar etwa in seinem Roman Schöne Freie Welt (München 1991, S. 44), in dem es über die Hauptfigur heißt: „Nebenbei begann Moran allmählich, sich in dieser Welt, die nicht die seine war und die zu begreifen ihm schwer möglich war, einigermaßen zurechtzufinden. Seine undurchschaubare Vergangenheit versetzte ihn nicht mehr so leicht in Panik, und selbst dann, wenn er, was wiederholt geschah, die Unfaßbarkeit, die Absurdität seiner Existenz empfand, verlor dies zunehmend seinen Schrecken.“

61 Paul Blaha: Interview vom 27.09.1995. In: Edith Pospichal: Paul Blaha - Journalist - Literat Kulturpolitiker. Ein biographischer Beitrag zum journalistischen, kulturellen und kulturpolitischen Schaffen eines Gesellschaftskritikers. Wien: Universität Wien, Dipl.-Arb. 1999, S. 169. 
dass er sich sehr konzentriere. Er war in der Lage, einen kraft seiner Person sehr einzunehmen. Er war eine Persönlichkeit, trotz seines nicht sehr einnehmenden Äußeren. ${ }^{62}$

Während Cab Calloway, Graham Greene, Jean Cocteau, Benjamin Britten und Orson Welles als berühmte Besucher die „internationale ausstrahlung “63 des „Art Club“ bestätigen, wähnt Ferry Radax Jean-Paul Sartre selbst als „Strohkoffer“-Gast: „Bis zum Herbst 1952 kamen so ziemlich alle Jazz- und Geistesgrößen Europas da herunter, weil es genauso heiß zuging wie in jedem Pariser Existenzialisten-Keller. Ich glaube, auch Jean-Paul Sartre war einmal hier."64 Auch wenn sich dies nicht bestätigen lässt, ist Friedrich Torberg in Anbetracht des bunten und „verheißungsvolle[n]“ Treibens der Ansicht: „daß das alles nun doch existiert, ist für Wiener Begriffe und Bedürfnisse Existentialismus genug“65. Tatsächlich werden der „Art Club“ und sein Kellerlokal auch ohne allzu evidente inhaltliche Anknüpfungspunkte zur französischen Geisteshaltung in der von der Presse geformten öffentlichen Wahrnehmung zum „Treffpunkt der Existentialisten Wiens": 66

Der ,Strohkoffer` war lange Zeit Wiens einzige Existentialistenattraktion und man zeigte sie allen Fremden, die nach so etwas suchten. Der amerikanische Tourist, der wie alle Amerikaner in Paris verliebt ist, sucht in Wien sonst vergeblich nach Montmartre-Atmosphäre oder Ähnlichkeiten mit der Kellergeneration von Saint-Germain-des-Prés. (Von diesem Pariser Künstlerquartier der Nachkriegszeit pflegt man zu sagen, dass es jener Ort auf dieser Welt ist, wo die Intelligenzdichte und die geistige Potenz am höchsten ist.) Als Jean Cocteau in Wien weilte, versäumte er es nicht, den Jüngern seiner Kunst einen kurzen Besuch abzustatten. Damals klebten sie wie Heringe in der Konservenbüchse aneinander und lauschten dem Evangelium des Meisters. ,Die Dichtung ist die Genauigkeit, das Zahlenmäßige‘, dozierte Cocteau. ${ }^{67}$

Noch konkreter: „Jede Stadt hat eine Spitze. In Paris ist es St. Germain des Prés, in Wien ist es der Art Club“68, zitiert der Maler Kurt Moldovan Jean Cocteau. In dessen Tagebuch findet sich am 27. Mai 1952 ein Eintrag über den „Art Club“, der im Stile der Saint-Germain-des-Prés-Keller doch eine eigene Wienerische Anmut besitze (,[l]'Art Club est une cave dans le style de Saint-Germain-des-

62 Paul Blaha. In: Ritschl: Zur Freiheit verurteilt. Der Siegeszug des Existenzialismus. Ö1, 08.04.2005. http://oe1.orf.at/artikel/207083 (einges. 09.01.2019).

63 Rühm: das phänomen „wiener gruppe“, S. 17.

64 Radax: Mit nichts als Fantasie erschufen wir unsere Welt aus dem Nichts, S. 41.

65 Friedrich Torberg: Post Scriptum. In: Wiener Kurier, 31.01.1952.

66 Z.-F.: Wiener Existentialisten flüchten ins „Exil“. In: Die Presse, 22.01.1955.

67 Z.-F.: Wiener Existentialisten flüchten ins „Exil“. In: Die Presse, 22.01.1955 (Hervorhebung im Original).

68 Kurt Moldovan: Cocteau im Art Club. Ein Situationsbericht (1952). In: Breicha (Hg.): Der Art Club in Österreich, S. 24-26, hier S. $24 \mathrm{f}$. 
Prés. [...] La cave est tapissée de ce qu'on appelle dans le midi des canisses. Nous sommes acclamés, entourés de soins, cinématographiés, photographiés, reçus avec cette grâce qui caractérise Vienne“669). Cocteau bringt die Wiener ExistentialistInnen durch seinen Besuch sogar auf die Leinwand. Der Beitrag „Wiener Artclub (,Der Strohkoffer‘), Wien“ mit Kinostart am 14. März 1952 in der Österreichischen Wochenschau, bestätigt den ZuschauerInnen die üblichen Klischees: Abgesehen von einem Flügel und einigen Skulpturen, dominieren in schwarze Rollkragenpullover gekleidete rauchende und trinkende junge Menschen mit Brillen und Bärten das Bild. Der Sprecher kommentiert:

Die jungen Künstler von Wien haben sich [...] ihr Heim eingerichtet, echter als in Paris. Tagsüber Galerie, ist der Strohkoffer [...] abends Treffpunkt von Komponisten, Schauspielern, Bildhauern, Schriftstellern und Kunstfreunden. Diskussion und Kritik erhitzen die Gemüter und Geister, die jüngsten und neuesten Werke zeigt man einander. In zwangloser, geselliger Zusammenkunft entsteht ein für Wien neuartiger Kontakt zwischen Künstlern und Publikum. Jean Cocteau ist schnell einmal von Paris nach Wien zu Besuch gekommen, fühlt sich bei uns wie der Herrgott in Frankreich und empfiehlt sich auch schon wieder auf Französisch ,Au revoir, c'est si bon, ich umarme euch'. Na überhaupt, wozu brauchen wir Paris [.....$^{70}$

Das kurze Filmporträt, das nebenhin widerspiegelt, wie die seit 1949 ausgestrahlte österreichische Wochenschau von „einem extrem lokalpatriotischen ,Wir““ geprägt ist, von Österreich als „Insel der Seligen“"71, fällt weniger mokant aus als die Darstellungen der Presse. Dort überwiegen „hämische artikel“, bisweilen eine regelrechte „feindseligkeit“, eine „atmosphäre von ignoranz und wütender ablehnung“72, so Rühm über die Reaktionen auf die künstlerische Avantgarde. Dass von dieser nichts Substantielles zu erwarten sei, scheint dabei als Grundannahme hindurch: „An den Wänden hängen Bilder. Man sieht sie, doch niemand schaut sie an. Alle reden, doch vergeblich wartet man, daß jemand tatsächlich etwas sagt.“" ${ }^{73}$ Stattdessen: Schlägerei, Krawall und Schaulustige, eine der Presse mehr als willkommene Trias, von der zuletzt Abschied genommen werden muss, als die „Strohkoffer“-Belegschaft ein neues Klublokal bezieht, nachdem „zu viele kamen, die nur gafften und nicht ,vom Fach“

69 Cocteau: Le Passé défini, S. 199.

70 o. V.: Wiener Artclub („Der Strohkoffer“), Wien (14. März 1952). In: Österreich in Bild und Ton 1952, DVD, 100 Min. Wien 2005.

71 o. V.: Geschichte im Überblick. In: 1949 in historischen Filmdokumenten. DVD, 72 min. (Edition Österreichische Wochenschauen) Wien 2007.

72 Rühm: das phänomen „wiener gruppe“, S. 17.

73 Z.-F.: Wiener Existentialisten flüchten ins „Exil“. In: Die Presse, 22.01.1955. 
waren, als es zu viele Raufereien gab und der Klub in Mißkredit zu geraten drohte $^{\text {“74 }}$. Auf Negativschlagzeilen bauende RedakteurInnen enttäuscht das Nachfolge-Lokal „Exil“, in dem es auf einmal „höchst solide“ zugeht, die Veranstaltungen erreichen „ein beachtliches Niveau“, die KünstlerInnen sind plötzlich nicht mehr „arbeitsscheu“75. So heißt es am 9. Dezember 1954 in der Tageszeitung Bild-Telegraf: „Zu ebener Erde geht es eben nicht so ,hitzig“ zu wie im Keller. Diese Tatsache läßt aber für die Zukunft vom ,Exil` doch einige ernsthafte künstlerische Äußerungen erhoffen.“76

Nach dem baldigen Ende von „Wiens Existentialistenlokal par excellence“77 kommt es in der zweiten Hälfte der fünfziger Jahre zu keiner vergleichbaren räumlichen Verdichtung mehr, auch wenn sich im Laufe der Zeit einzelne ProtagonistInnen und kleinere Kreise im „Dom-Café“ (Singerstraße), „Espresso Stambul“ (Fleischmarkt) und im „Gutruf“ (Milchstraße) einfinden, und sich etwa das in der Dorotheergasse gelegene „Café Hawelka“ mit Gästen wie H. C. Artmann, Oswald Wiener und Gerhard Rühm ,als existenzialistisch angehauchter Literaturtreff“ ${ }^{78}$ verstanden wissen will. Als „,[ü]berfüllt“ und „sakralisiert nachträglich durch Bayer und die Wiener gruppe, die es längst nicht mehr gab“, bezeichnet es der Literaturwissenschaftler Mayer, womit es ihm wie ein „Wiener Gegenstück zum Pariser Café de Flore nach dem Auszug von Sartre“79 erscheint. $\mathrm{Zu}$ einer Alternative entwickelt sich das „Café Sport“ in der Schönlaterngasse, das für sein Publikum „das Versprechen birgt, dass es einen way out aus diesem unerträglichen, kleinbürgerlichen Autoritarismus gibt“; Franz Schuh nennt es „eine Richtungsentscheidung, ob man ins Café Hawelka geht oder ins Café Sport“, denn Letzteres war

metaphorisch gesagt, so etwas wie ein Kaffeehaus für die Fremdenlegionäre der Stadt, ein wüstes Lokal mit Musikbox und einer verdrehten Auffassung von Freiheit. Es war wunderbar! Auch das soll man logischerweise nicht romantisieren. Soziologisch betrachtet, gab es dort die ersten Rauschgiftopfer und Alkoholiker meiner Generation. ${ }^{80}$

Rausch und Existentialismus verbinden sich an diesem Ort im Dichter Walter Buchebner, dessen Gedichte sich als „aggressive Zeitkritik“ gegen „den selbst-

74 Z.-F.: Wiener Existentialisten flüchten ins „Exil“. In: Die Presse, 22.01.1955.

75 Z.-F.: Wiener Existentialisten flüchten ins „Exil“. In: Die Presse, 22.01.1955.

76 L.: Bärte und Kunst sind im „Exil“. In: Bild-Telegraf, 09.12.1954.

77 Z.-F.: Wiener Existentialisten flüchten ins „Exil“. In: Die Presse, 22.01.1955.

78 Café Leopold Hawelka: Prominente Gäste im Hawelka. http://www.hawelka.at/cafe/de/pro minente-gaeste/ (einges. 09.01.2019).

79 Mayer: Die umerzogene Literatur, S. 212.

80 Franz Schuh: Warten auf nichts. In: Sepp Dreissinger: Im Kaffeehaus. Gespräche. Fotografien. Wien 2017, S. 146-152, hier S. 148 f. (Hervorhebung im Original). 


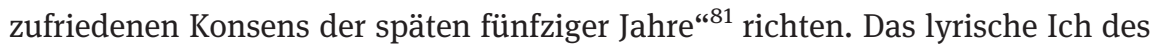
Gedichts „die revolte“ beispielsweise trinkt 1961 im „Café Sport“ Rotwein, hört Chansons und plant einen Aufstand gegen die „museale poesie“, eine Revolte gegen das ,alte' Schreiben (cf. Kap. 6.4):
i c h
beginne neue gedichte zu schreiben ich überlege die literarische revolte ich über-
lege die revolte die ich zu starten
gedenke und paula bringt mir wein ich sehne
mich nach rauschgift meine reise nach
paris wird mir die quellen öffnen ich will
mein temperament entfesseln meinen ver-
stand entfesseln meine sinne entfesseln ${ }^{82}$

Buchebner, der hier mit der „hoffnungslosigkeit und der trauer dieser stadt“ schließt, setzt in seinem Gedicht „paris ma poésie“ an mit „ich sage euch: wien ist schön aber zum / kotzen gegen paris!“, und endet mit einem Aufrufen Sartres als (bislang) unsterbliche Wasserschlange:

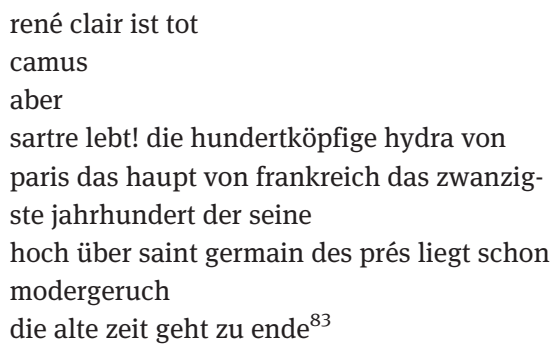

Neigt sich die alte Zeit ihrem Ende zu, kann das Verebben der „Welle des Pseudo-Existentialismus“ in „den Niederungen des Fremden-Amüsements und der Sensationsreportagen“"84 den Weg zu einer tieferen Beschäftigung mit der inzwischen übersetzten existentialistischen Literatur frei machen. Auch die zur nächsten SchriftstellerInnengeneration gehörenden jüngsten ZeitzeugInnen

81 Kriegleder: Die Literatur der fünfziger Jahre in Österreich, S. 43.

82 Walter Buchebner: die revolte. In: Buchebner: ich die eule von wien. Gedichte, Manifeste, Tagebücher, mit 28 bildnerischen Arbeiten des Autors und einem Essay von Marlene Streeruwitz. Hg. und mit einem Nachwort von Daniela Strigl. Wien 22012, S. 161-167, hier S. 161 (Hervorhebung im Original).

83 Walter Buchebner: paris ma poésie. In: Buchebner: ich die eule von wien, S. 154-160, hier S. $155 \mathrm{f}$.

84 Mayer: Metaphysik und Bee-Bop. In: Die Zeit, 17.05.1951. 
rezipieren das diesbezüglich Gelesene oder Gesehene noch und lassen den Existentialismus als subkulturelles, jedoch ebenfalls als philosophisches Phänomen in ihrer Prosa aufleben. So werden existentialistische Theaterstücke zwar seit Ende der vierziger Jahre besucht, ihre Bücher gelesen, doch der wahre Umfang ihrer Wirkung auf die literarische Produktion (,impact réel sur la production littéraire“65) lässt sich erst einige Jahrzehnte später ermessen.

\subsection{Literarische Darstellungen des Existentialismus als Jugendkult}

Um den Preis der inhaltlichen Verflachung erreicht der Existentialismus wenige Monate nach Kriegsende in Frankreich den Status einer Jugendbewegung, in einem solchen Ausmaß, dass ein Aufgreifen durch SchriftstellerInnen nicht lang auf sich warten lässt. Am Beginn des literarisch sich niederschlagenden ,Kultes“ steht in Frankreich Boris Vians zunächst in Les Temps modernes (Oktober 1946, Nr. 13) auszugsweise vorgestellter Roman L'Écume des jours (1947). Erfolg ist Vians erstem abgeschlossenem Werk nicht beschieden, erst durch die Neuauflage 1963, vier Jahre nach seinem Tod, avanciert es zum ausserordentlichen und langfristigen Erfolg. ${ }^{86}$ Seine literaturgeschichtliche Relevanz würdigt 1968 Leslie Fiedler in seinem einflussreichen Aufsatz „Cross the Border - Close the Gap“, in dem er fordert, die Kluft zwischen Eliten- und Massenkultur zu überwinden und die ,alte“ Literatur der Moderne als „not dying, but dead“ hinter sich zu lassen, was Vian, dem „prototype of the New Novelist“, am besten gelinge:

[H]e managed to straddle the border, if not quite close the gap between high culture and low, belles-lettres and pop art. On the one hand, he was the writer of pop songs and a jazz trumpeter much influenced by New Orleans style; and on the other, the author of novels in which the thinly disguised figures of such standard French intellectuals as Jean Paul Sartre and Simone de Beauvoir are satirized. ${ }^{87}$

Vian - Ingenieur, Musiker, Kritiker, Schriftsteller, Schauspieler - verweigert sich allen Festlegungen, auch auf den Existentialismus (,,[j]e ne suis pas existentialiste. En effet, pour un existentialiste, l'existence précède l'essence. Pour

85 Feindt: Engagement, empathie, distanciation, S. 71.

86 Cf. Gilbert Pestureau: Introduction. In: Boris Vian: L’Écume des jours. Édition établie, présentée et annotée par Gilbert Pestureau et Michel Rybalka. Paris 1998, S. 5-11, hier S. 7.

87 Leslie Fiedler: Cross the Border - Close the Gap (1970). In: Fiedler: A New Fiedler Reader. Amherst/NY 1999, S. 271-294, hier S. 274, 277. [Zuerst in dieser Fassung in: Playboy, Dezember 1969.] 
moi, il n'y a pas d'essence“"88), gibt aber als „the epitome of Left Bank bohemia“ ${ }^{89}$ in seinem Manuel de Saint-Germain-des-Prés den heiteren Chronisten des Rive Gauche-Geschehens. Darin taucht Sartre als sympathischer Mensch auf, der es durchaus verdiene, in Frieden gelassen zu werden („qui mériterait bien qu'on lui foute un peu la paix, parce que c'est un chic type“90). Vians Wahrnehmungen der Subkultur aus nächster Nähe werden in L'Écume des jours handlungstragend: Die Existentialismus-Satire speist sich vor allem aus der Verfallenheit der Figur Chick an den Philosophen Jean-Sol Partre, ein Star, dessen aus einigen Ideen und einigem Überflüssigem bestehende Schriften (,un peu d'idées et un peu de superflu“91) inhaltlich nicht einmal von sekundärer Bedeutung sind. Größte Aufmerksamkeit kommt hingegen bibliophilen Partre-Ausgaben (von Le Vomi, angelehnt an Sartres La Nausée, oder, wiederum ein Wortspiel, La Lettre et le Néon, bei dem es sich im Gegensatz zu Sartres L'Être et le Néant um eine bekannte Leuchtschilder-Studie handle) sowie Memorabilia zu, etwa einer Pfeife, die Partres Zahnabdruck trägt und dem Sammler Chick trotz des hohen Preises nicht fehlen darf („[ç]a me coûte très cher, mais je ne peux pas m'en passer, dit-il. J'ai besoin de Partre. Je suis collectionneur. Il me faut tout ce qu'il a fait“92). Vian lässt Chicks Begeisterung zu einem Wahn anwachsen, der sich auch auf die anderen Figuren auswirkt: auf dessen Freundin Alise, die sein Zugrundegehen rächt, in dem sie Partre schließlich tötet und Buchhandlungen in Flammen setzt, sowie auf den Freund Colin, der ihm viel Geld leiht und sich und seine Partnerin auf diese Weise selbst in den Ruin treibt.

Partre selbst tritt im Roman zweimal in Erscheinung, zunächst bei einer Konferenz, die Sartres berühmtem L'Existentialisme est un humanisme-Vortrag nachempfunden ist. Die versammelte AnhängerInnenschaft - wiedererkennbar dank spezifischen Merkmalskombinationen aus struppigen Haaren, Brillen und Zigarettenstummeln (,visages fuyants à lunettes, cheveux hérissés, mégots jaunis“93) fiebert ihrer Ikone entgegen, die sich in den Straßen durch trompetende Elefanten ankündigt. Zahlreich sind die Ohnmachten, gering die Interessensbekundungen an Inhalten: Im bewundernden Geschrei geht der Text unter („[1]e public [...] manifestait son admiration pour Partre à grand renfort de cris et d'acclamations chaque fois qu'il disait un mot, ce qui rendait assez difficile la compréhension

88 Boris Vian: Sartre et la merde. In: Arnaud: Les Vies parallèles de Boris Vian, S. 261-263, hier S. 263. [Zuerst in: La Rue, 12.07.1946.]

89 Dan Halpern: Prince of Saint-Germain. In: The New Yorker, 25.12.2006.

90 Vian: Manuel de Saint-Germain-des-Prés, S. 203.

91 Vian: L’Écume des jours, S. 264.

92 Vian: L’Écume des jours, S. 70; cf. S. 200, 201.

93 Vian: L’Écume des jours, S. 134. 
parfaite du texte“94). Als schließlich der Plafond einstürzt und ZuschauerInnen unter sich begräbt, kann bei einem auf Extremsituationen (cf. Kap. 6.3) eingestellten Denker nur Freude aufkommen („Partre s'était arrêté et riait de bon cœur en se tapant sur les cuisses, heureux de voir tant de gens engagés dans cette aventure“95). Vergleicht man Vians Schilderung dieser Szene mit den Erinnerungen Simone de Beauvoirs (in L'Écume des jours als herzogliche ,Duchesse de Bovouard“ karikiert), zeigt sich die Notwendigkeit der drastischen Überzeichnung einer Situation, die realiter schon einem Ausnahmezustand nahekommt, da auch hier das Gedränge einer Menschenmasse für Ohnmachtsanfälle sorgt („,[à] la conférence de Sartre, il vint une telle foule que la salle ne put la contenir: ce fut une bousculade

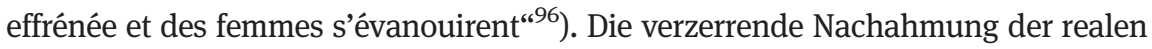
Person Sartre und seiner Gefolgschaft in L'Écume des jours hat, zumal durch die Vielzahl an neosurrealistischen und sprachspielerischen Elementen (Spoonerismen, Portemanteau-Wörter), mehr komisches denn offen kritisches Potential. ${ }^{97}$

Eine stärker auf existentialistische Inhalte gerichtete Darstellung der auch dort destruktive Kräfte entfaltenden Mode liefern Elfriede Jelineks Die Ausgesperrten (1980) und Norbert Gstreins Eine Ahnung vom Anfang (2013), die über die höchste Dichte an Sartre- und Camus-Verweisen in der österreichischen Nachkriegsprosa verfügen. Jelinek verlegt die Handlung ihres im Todesjahr Sartres veröffentlichten Romans über vier strauchelnde Wiener Jugendliche - die Kleinbürger-Zwillinge Rainer und Anna Witkowski, der Arbeiter Hans sowie die aus wohlhabendem Hause stammende Sophie - in die Spätfünfziger und damit in eine besonders ,enge geistige und kulturelle Atmosphäre“98, für die nicht mehr gilt, was laut Beauvoir nach 1945 der Fall ist: zu Kriegsende jung zu sein, erscheint als enorme Chance („une énorme chance“999); offen, so Jean Améry in ähnlichen Tönen, gibt sich die „Zukunft, in die der junge Mensch hineintaumelt ${ }^{\star 100}$ in jenen Tagen. Im Folgejahrzehnt dagegen:

Die offiziellen und offiziösen Anstrengungen zur Vermittlung und Verinnerlichung von Werten der Respektabilität und Solidität sind sonder Zahl, zielen auf eine durch Krieg und Faschismus zutiefst traumatisierte Generation und propagieren den klassisch fordistischen

94 Vian: L’Écume des jours, S. 136.

95 Vian: L'Écume des jours, S. 139.

96 Beauvoir: La Force des choses, Bd. 1, S. 61.

97 Cf. Gilbert Pestureau: Langue. In: Vian: L’Écume des jours, S. 309-312, hier S. 311.

98 Heinrich Deisl: Im Puls der Nacht. Sub- und Populärkultur in Wien, 1955-1976. Wien, Berlin 2013, S. 74.

99 Beauvoir: La Force des choses, Bd. 1, S. 21.

100 Améry: Über das Altern, S. 28. 
Wertekanon, einen um Kleinfamilie und Wohnung zentrierten, ebenso disziplinierten wie homogen-gleichförmigen Lebensstil. ${ }^{101}$

Die hier von Wolfgang Maderthaner und Lutz Musner beschriebene Wiederkehr des Immergleichen gehört für die eingeengte Jugend zu den ausschlaggebenden Motiven für den Kulturimport des Existentialismus. Ihre Erwartungen erfüllt er mit einem im Kontrast zum (klein)bürgerlichen Konformismus stehenden individualistischen Identifikationsangebot. ${ }^{102}$ Er bewährt sich damit auch als Antihaltung gegen eine Wiederaufbaugesellschaft, deren einstige geistige Leitlinien versagt haben und nun offiziell dem Vergessen anheimgegeben werden.

Dass Jelineks Wien von 1959 nach „Abenteuer, Jazzmusik, Cafés und Auspuffgasen“ riecht, da und dort noch mit ein wenig Dreck und Staub „von den Baustellen, die letzte Ruinen wegräumen und Wien noch schöner machen sollen“103, lässt keinen Zweifel: Wiederaufbau bedeutet „Beseitigung der sichtbaren Kriegsfolgen“104, nicht der schwer zu beseitigenden immateriellen Überreste. Die in den Nationalsozialismus involvierte Elterngeneration verkörpert hier der von „Pflicht“ schwadronierende Zwillingsvater Witkowski, ein kriegsversehrter ehemaliger SS-Angehöriger, der nun guten Gewissens die Familie malträtiert: „Die Geschichte hat sich nach 45 entschlossen, noch einmal ganz von vorne zu beginnen, zu demselben Entschluß hat sich auch die Unschuld durchgerungen." ${ }^{\text {"105 }}$ Sich gegen diese Generation aufzulehnen ist in das Wesen ihrer Kinder früh eingeschrieben, so der selbst schon 1932 in die SA eingetretene Helmut Schelsky in seiner Studie Die skeptische Generation: Durch Kriegs- und Nachkriegsnöte sehen sie sich schon in jungen Jahren ,in die Lage versetzt, für den Aufbau und die Stabilisierung ihres privaten Daseins Verantwortung oder Mitverantwortung übernehmen zu müssen“106. Obgleich in „den Überlebensprozess integriert d. h. als Erwachsene behandelt“, werden sie dennoch „als ,Kinder‘ gemaßregelt

101 Wolfgang Maderthaner und Lutz Musner: Im Schatten des Fordismus - Wien 1950 bis 1970. In: Horak et al. (Hg.): Randzone. Zur Theorie und Archäologie von Massenkultur in Wien 1950-1970. (Kultur.Wissenschaften 10.) Wien 2004, S. 31-54, hier S. $44 \mathrm{f}$.

102 Ähnlich reagiert die Jugend in Westdeutschland auf den Existentialismus: „Die große Resonanz, die er findet, gründet sich auf der fundamentalen Erschütterung alles dessen, was dem Leben der Menschen vor dem Krieg Sinn verliehen hat: Religion, Familie, Volksgemeinschaft.“ Dieter Felbick: Schlagwörter der Nachkriegszeit 1945-1949. Berlin, New York 2003, S. 266.

103 Elfriede Jelinek: Die Ausgesperrten. Reinbek 1989 [1980], S. 226, 131.

104 Dvořak: Thesen zur sozikulturellen Entwicklung in Österreich 1933 bis 1955, S. 31.

105 Jelinek: Die Ausgesperrten, S. 184, 98. Cf. Sylvia Paulischin-Hovdar: Der Opfermythos bei Elfriede Jelinek. Eine historiografische Untersuchung. (Literatur und Leben 88.) Wien, Köln, Weimar 2017.

106 Helmut Schelsky: Die skeptische Generation. Eine Soziologie der deutschen Jugend. Düsseldorf, Köln 1957, S. 86. 
und kontrolliert“, betont Oliver Rathkolb: „Aus diesen Widersprüchen heraus entwickelte sich eine Protestkultur, die besonders in den Städten sichtbar wurde, sich aber nur in einer ,schockierenden' Freizeitgestaltung und einer steigenden Jugendkriminalität erschöpfte.“107 Diese Zeiterscheinung, „eine auffällige Zunahme öffentlicher Randale auf den Straßen größerer Städte“108, porträtiert Jelineks Roman in Form von wahllosen Überfällen auf Passanten durch ihre jugendlichen Figuren Sophie, Anna, Hans und Rainer, denen Gewalt um der Gewalt willen vorschwebt.

Der existentialistische Kerntopos des acte gratuit wird bereits 1899 und 1914 in André Gides Prosa als absichts- und zielloser Akt ausführlich theoretisiert („désintéressé; né de soi; l'acte aussi sans but; donc sans maître; l'acte libre; l'Acte autochtone“), demgegenüber es nichts Demoralisierenderes (,rien de plus démoralisant“109) gebe. Dass der Mensch, der ein unmotiviertes Verbrechen (,[u]n crime immotivé“) begeht, frei wird („homme libre“110), die Willkür also „die Freiheit vor ihrer Domestikation“"111 darstellt, wird von Jelineks Jugendlichen wiederholt debattiert. Ihre Überfälle sollen als „Selbstzweck“ und „Sinnloses aus Prinzip“ nicht auf Determination rückführbar sein und somit ihre Freiheit bestätigen, was jedoch nur bedingt funktioniert: „Gerade das Unnötige ist das Prinzip. Ich finde das Nötige aber noch besser, sagt Hans, der seltsamerweise Geld liebt, und beäugt das Portemonnaie. Geld ist unwichtig, bespuckt Rainer die Brieftasche, was meinst, sind das Hunderter oder Tausender da drinnen?“"112 Während in Bezug auf die Willkürtaten Camus' L’Étranger

107 Oliver Rathkolb: Es ist schwer, jung zu sein. Jugend und Demokratie in Österreich 19181988. Wien 1988, S. 125.

108 Jürgen Zinnecker: Jugendkultur 1940-1985, hg. vom Jugendwerk der Deutschen Shell. Opladen 1987, S. 125f. Das Phänomen dauert an, wie Sartres Rede (Abrüstung der Kultur, S. 1) auf dem „Weltkongress für allgemeine Abrüstung und Frieden“ 1962 in Moskau meint: „Eine Gefahr droht: die Zahl jener, die man bei uns ,blousons noirs‘, anderswo ,Hooligans“ oder ,Halbstarke“ nennt, ist im Steigen begriffen. Wir können und müssen von diesen jungen Leuten sagen, welche Untaten sie auch begehen, daß wir für sie verantwortlich sind, daß wir in diesen fünfzehn letzten Jahren es nicht verstanden haben, ihnen ein klares Bewußtsein zu geben über sich selbst, über ihre Klasse, über die Entfremdung, unter der sie leiden, daß wir diese nackten und wilden Gewalttaten zugelassen haben, weil wir sie nicht aufgeklärt und geführt haben.“

109 André Gide: Le Prométhée mal enchaîné. Paris 1941, S. 21, 23. Für nähere Untersuchungen des Topos cf. Martin Raether: Der „Acte gratuit“. Revolte und Literatur. Hegel, Dostojewskij, Nietzsche, Gide, Sartre, Camus, Beckett. (Studia Romanica 37.) Heidelberg 1980; sowie Volker Roloff: Der Mörder als Erzähler: Existentialismus und Intertextualität bei Sartre, Camus, Cela und Sábato. In: Romanistische Zeitschrift für Literaturgeschichte 10 (1986), Nr. 1/2, S. 197-218. 110 André Gide: Les Caves du Vatican. Paris 1922, S. 194, 207.

111 Hans Saner: Die Anarchie der Stille. Basel 1990, S. 148.

112 Jelinek: Die Ausgesperrten, S. 11, 129, 8 f. 
im Roman mehrfach zur Sprache kommt (cf. Kap. 6.3), spielt eine zentrale acte gratuit-Darstellung Sartres (,un acte proprement impolitique“113), die Erzählung „Érostrate“ aus dem Band Le Mur, keine Rolle in Die Ausgesperrten. In Sartres Erzählung führt die misanthropische Hauptfigur jene Tat aus, die André Breton einst als einfachsten surrealistischen Akt bezeichnet hat, daraus bestehend, mit einem Revolver auf die Straße zu laufen und wahllos in die Menge zu schießen (,revolvers aux poings, à descendre dans la rue et à tirer au hasard, tant qu'on peut, dans la foule“114). Stattdessen dient Jelineks Jugendlichen eine Szene aus Sartres zweitem Roman L'Age de raison (1945) als direkte Handlungsanweisung:

In der Zeit der Reife von Jean-Paul Sartre will einer seine Katzen ersäufen, und deshalb will man heute diese Katze ebenfalls ersäufen, obwohl auch diese Katze ein Recht auf ihre Existenz hat. Rainer sagt, er selber hat ebenso das Recht auf seine Nichtexistenz, genau wie diese Katze hier, welche von ihm in ihre Nichtexistenz befördert werden wird, eh sie noch bis drei zählen kann. ${ }^{115}$

Während das Unterfangen hier im letzten Moment durch eine Störung von außen scheitert, hält die Inspirationsfigur Daniel aus L'Âge de raison zuletzt die philosophische Erkenntnis ab, sich selbst auch durch die Tat nicht erreichen zu können (,[u]n grand dégoût l'envahit, il pensa: ,C’est un acte gratuit.“ Il s'était arrêté, il avait posé le panier par terre: ,S’emmerder à travers le mal qu'on fait aux autres. On ne peut jamais s’atteindre directement““116).

Nicht nur als Handlungsvorlage und -legitimation dienen existentialistische Elemente in Die Ausgesperrten, sondern insbesondere „um sich ins rechte Licht zu setzen“"117 werden Sartre und Camus plagiiert und paraphrasiert, vor allem von Rainer, der unaufhörlich über „philosophische Problemstellungen“ diskutiert, beispielsweise „über innere künstlerische Spannungen, die er am Beispiel von Camus nachweist“"118 . Die großen Namen fungieren als Platzhalter für eigene Denkinhalte (ähnlich wie bei Vians Partre-Anhänger Chick, der einsieht, dass Partre alles sagt, was er selbst gern sagen können wollte - „Partre

113 Jean-Paul Sartre: Érostrate. In: Sartre: Euvres romanesques, S. 262-278, hier S. 271 (Hervorhebung im Original).

114 André Breton: Second Manifeste du Surréalisme (1930). In: Breton: Manifestes du Surréalisme. Paris 1962, S. $155 \mathrm{f}$.

115 Jelinek: Die Ausgesperrten, S. 92. Dass der Titel von Sartres Roman hier nicht in Anführungszeichen gesetzt wird, unterstreicht für Marlies Janz (Elfriede Jelinek, S. 48), wie die Figuren „fiction und non-fiction miteinander verwechseln“.

116 Jean-Paul Sartre: L’Âge de raison. In: Sartre: Euvres romanesques, S. 391-729, hier S. 486.

117 Jelinek: Die Ausgesperrten, S. 95.

118 Jelinek: Die Ausgesperrten, S. 164, 232. 
dit tout ce qu'il voudrait savoir dire“119), doch extrahiert Rainer nur diejenigen Elemente aus Sartres Denken, die ihm zupasskommen. An ihm veranschaulicht sich deutlich Jelineks Auskunft, sie schreibe ,über Personen, wie sie sich als Sprachschablonen oder Sprachmuster materialisieren“"120. Rainer, der „Herr Professor“ genannte Anführer der von seinen intellektuellen Ausbrüchen gelangweilten Gruppe, steht im Ruf, ein Angeber zu sein, „der dauernd Sachen sagt, die nicht wahr sind“, obwohl man doch wahrhaftig sein müsse; zudem sage er „nie einen Satz, den ein anderer nicht schon gesagt hat“121. Auch Sätze Sartres gibt er als die seinen aus, etwa als er seinen Freunden gegenüber ungefragt über „Wollust“ referiert (,[w]ißt ihr, das Bewußtsein ist in dieser Exstase nur noch Bewußtsein des Körpers und daher reflexives Bewußtsein von der Leiblichkeit"“122) und sich damit aus der Erstübersetzung von Das Sein und das Nichts bedient: „[D]ie Wollust ist eine Art von besonderer Ekstase, in der das Bewußtsein nur noch Bewußtsein (des) Leibes ist und infolgedessen reflexives Bewußtsein von der Leiblichkeit wird.“123 Auch seine Schwester Anna hat „den ganzen Sartre in [ihrer] Freizeit gelesen, das ganze Sein und das ganze Nichts“, wohl wissend, dass dies sie von „Millionen anderer Mädchen“ ${ }^{124}$ unterscheidet. Als besonders präsenter Prätext scheint Sartres erster Roman Der Ekel durch verschiedene wörtliche Übernahmen auf, im Folgenden ohne Markierung: „Rainer hat genug von diesen Ideen über die Vergangenheit, die Gegenwart, die Welt. Er verlangt nur eines: man soll ihn in Ruhe sein Buch beenden lassen, das er schreiben will. “125 In den Aufzeichnungen der Hauptfigur Sartres, Roquentin, steht zu lesen: „Ich hatte genug, übergenug von diesen Ideen über die Vergangenheit, die Gegenwart, die

119 Vian: L’Écume des jours, S. 263.

120 Elfriede Jelinek. In: Riki Winter: Gespräch mit Elfriede Jelinek. In: Bartsch und Höfler (Hg.): Elfriede Jelinek. (Dossier 2.) Graz, Wien 1991, S. 9-19, hier S. 13.

121 Jelinek: Die Ausgesperrten, S. 21, 165, 256.

122 Jelinek: Die Ausgesperrten, S. 21 (Hervorhebung im Original).

123 Jean-Paul Sartre: Das Sein und das Nichts. Versuch einer phänomenologischen Ontologie. Deutsch von Justus Streller, Karl August Ott und Alexa Wagner. Hamburg 1974, S. 508. Cf. Sartre: L'Être et le Néant, S. 437: „A vrai dire, il est normal que l'engluement de la conscience dans le corps ait son aboutissement, c'est-à-dire une sorte d'extase particulière où la conscience ne soit plus que conscience (du) corps et, par suite, conscience réflexive de la corporéité.“ (Hervorhebung im Original).

124 Jelinek: Die Ausgesperrten, S. 89.

125 Jelinek: Die Ausgesperrten, S. 60. 
Welt. Ich verlangte nur eines: man solle mich in Ruhe mein Buch beenden lassen. “" ${ }^{126}$ Eine andere, frei übernommene Passage bei Jelinek lautet:

Jetzt, in dem Moment hat ihn endlich der Ekel ergriffen, so daß er die Feder fallen läßt, mit der er eine Gedichtzeile ins Notizbuch notieren wollte, die Tinte verspritzt nutzlos. War es jetzt der Ekel oder nicht? Nein, er war es doch eher nicht. Der Raum sieht so spießig aus wie immer. Kaum, daß er ihm etwas schwerer, dicker oder kompakter erschiene. ${ }^{127}$

In der Jelinek seinerzeit zur Verfügung stehenden ersten Übersetzung von $L a$ Nausée heißt es:

Auf einmal packte es mich, die Feder fiel mir aus der Hand, die Tinte verspritzte. Was war los? Hatte mich der Ekel gepackt? Nein, das war es nicht. Das Zimmer sah so spießig aus wie immer. Kaum, daß mir der Tisch etwas schwerer, dicker erschien und mein Füllhalter etwas kompakter. ${ }^{128}$

Nach dieser Szene gelangt Roquentin zu der Erkenntnis, dass die Vergangenheit nicht existiert und somit auch nicht sein im frühen 19. Jahrhundert verstorbenes Studienobjekt, ein gewisser Marquis de Rollebon, was er als unersetzlichen Verlust empfindet: „Wenn von ihm noch ein paar Knochen blieben, so existierten sie ganz für sich selbst, in voller Unabhängigkeit, sie waren nichts als ein bißchen Phosphat und Kalk, Salze und Wasser. [...] [E]s war nur ein Abbild in mir selbst, eine Fiktion." ${ }^{129}$ Rainer Witkowskis Paraphrase wird, als dritte Variante, mit einem Hinweis auf die entlehnten Gedanken versehen:

Aber er hat, wie Sartre, begriffen, daß die Vergangenheit nicht existiert. Und die Knochen der Getöteten und Verstorbenen, auch der im Bett Verschiedenen, sie existieren ganz für sich selbst, in größter Unabhängigkeit, nichts als ein bißchen Phosphat, Kalk, Salze und Wasser. Ihre Gesichter sind nur Abbilder in Rainer selbst, Fiktion. Eben jetzt empfindet er

126 Jean-Paul Sartre: Der Ekel. Deutsch von Heinrich Wallfisch. Stuttgart, Hamburg, BadenBaden 1949, S. 130. Cf. Sartre: La Nausée, S. 137: „[J]'en avais par-dessus la tête, de ces réflexions sur le passé, sur le présent, sur le monde. Je ne demandais qu'une chose: qu'on me laisse tranquillement achever mon livre.“

127 Jelinek: Die Ausgesperrten, S. 106.

128 Jean-Paul Sartre: Der Ekel, S. 131. Cf. Sartre: La Nausée, S. 137 f.: „Un immense écœurement m'envahit soudain et la plume me tomba des doigts en crachant de l'encre. Qu'est-ce qui s'était passé? Avais-je la Nausée? Non, ce n'était pas cela, la chambre avait son air paterne de tous les jours. C'était à peine si la table me semblait plus lourde, plus épaisse et mon stylo plus compact.“

129 Sartre: Der Ekel, S. 132. Cf. Sartre: La Nausée, S. 139: „S’il restait encore de lui quelques os, ils existaient pour eux-mêmes, en toute indépendance, ils n'étaient plus qu'un peu de phosphate et de carbonate de chaux avec des sels et de l'eau. [...] Seulement ce n'était plus qu'une image en moi, une fiction.“ 
das sehr stark, es ist ein Verlust. Er sagt aber keinem, daß vor ihm schon Jean-Paul Sartre diesen Verlust genauso gefühlt hat, er gibt es als seinen eigenen Verlust aus. ${ }^{130}$

Neben direkten Anleihen aus Sartres Zeit der Reife, Das Sein und das Nichts und vor allem Der Ekel ${ }^{131}$ kommen existentialistische Schlüsselideen mehr oder minder verfremdet zum Vorschein und zu unmittelbarer Anwendung:

Tatsächlich sind wir eine Freiheit, die wählt, aber wir wählen nicht, frei zu sein. Wir sind zur Freiheit verurteilt. Wenn ich dich anschau, Mama, so stimmt das. In der Freiheit verlassen, was auf dich zutrifft. Und diese Verlassenheit hat keinen anderen Ursprung als eben die Existenz der Freiheit. Das sieht man an dir. [...] Die Zwillinge erklären der Mutter, daß auch die Nichtexistenz dieser Mutter denkbar und möglich wäre. Ich habe euch persönlich geboren, einen nach dem anderen. Daher existiert ihr, und ich existiere auch. Was ist das für ein Blödsinn. [...] Die Mutter wird wie eine Stubenfliege verscheucht. ${ }^{132}$

Lassen Jelineks sprachliche Verfahren „den Betrachter bewusst im Unklaren [...], ob es sich um Mimesis oder Parodie handelt“133, so scheint hier genau jener Gebrauch von literarischen Figuren als Ideologie-Kanäle parodiert, der Sartre mit Blick auf sein fiktionales Werk oft vorgehalten wurde. Die von Jelineks Jugendlichen verwendete Sprechweise wird als existentialistisches Gehabe dekonstruiert, bei Rainer sowie bei denen, die ihm (ohne Rücksicht auf Differenzen zwischen Sartre und Camus) nachsprechen, wie Hans Sepp: „Hans sagt der Mutter, daß sich der Mensch befreien muß und revoltiert [!], dann beginnt ein Leben ohne Zwänge, wie der Rainer immer sagt.“" ${ }^{\text {‘34 }}$ Diese Freiheit müsse „ein für alle mal“ erlangt werden, ungeachtet der eigentlichen philosophischen Vorgabe, dass diese Freiheit „streng bedingt durch ihre korrelative Unfreiheit“ ist, wie Améry den Sartreschen Faktizität-Begriff einmal umschreibt, sie ist „ein permanenter Prozeß“ und „kein ein für allemal zu erobernder unveränderlicher Raum““135. An Rainers und Hans' Glauben, sich von allen Determinierungen lösen zu können, stößt sich vor allem Hans' Mutter. Die Arbeiterin Frau Sepp vertritt in der Literatur die in den ersten fünf Nachkriegsjahren laute kommunistische Kritik an der existentialistischen Außerachtlassung von Lebensumständen, indem sie sich gegen einen

130 Jelinek: Die Ausgesperrten, S. $106 \mathrm{f}$.

131 Sartre und Camus stellen in Jelineks Roman die meisten Prätexte, hinzu kommen Verweise unter anderem auf Roland Barthes, Marquis de Sade, Georges Bataille, Jean Cocteau, Immanuel Kant und G. W. F. Hegel.

132 Jelinek: Die Ausgesperrten, S. $41 \mathrm{f}$.

133 Carolin John-Wenndorf: Der öffentliche Autor. Über die Selbstinszenierung von Schriftstellern. Bielefeld 2014, S. 148.

134 Jelinek: Die Ausgesperrten, S. 228.

135 Jean Améry: Hand an sich legen: Diskurs über den Freitod. Stuttgart 1983 S. 128, 129. 
Freiheitsbegriff wendet, der verwaschen sei, da man sich nicht „im luftleeren Raum“ befinde, sondern „gesellschaftlich bedingt“ sei:

Hans sagt, er steht über dem luftleeren Raum der Normalbürger, in dem man leicht erstickt.Die Mutter säbelt Brot ab, [...] und gibt ihrem irgendwie unrichtig geratenen Sohn $\mathrm{zu}$ bedenken, daß er sich gerade dadurch zum Bürger macht. Indem du dich scheinbar über sein Wertsystem stellst, erkennst du es an. Es macht dich blind gegenüber Elend. Schon daß du über ,den Menschen' redest, ist ein Verbrechen, denn diesen universellen Menschen gibt es nicht, nie und nimmer, es gibt den Arbeiter und es gibt den Ausbeuter des Arbeiters und dessen Helfershelfer. Hans sagt, der Rainer sagt, es graust einem bei der Vorstellung, ein Teil von einem Ganzen zu sein. Weil man immer ein einzelner und vollständig allein, dabei aber unverwechselbar ist, was stärkt. ${ }^{136}$

Auch wenn während der Handlungszeit des Romans, 1959, Sartres Auseinandersetzung mit dem historischen Materialismus seine Freiheitsauffassung längst beschränkt hat, nimmt Jelinek den frühen Sartre, der den KommunistInnen die größte Angriffsfläche geboten hat, als Folie. Rezeptionsgeschichtlich ergibt dies Sinn, denn Anknüpfungspunkt für die junge Generation bleibt weit über die Erstaufnahme des Existentialismus hinaus der Vorkriegsschriftsteller, der Einzelgänger („homme seule“137) Sartre. Dessen Helden verkörpern, wie auch jene von Camus oder Malraux, das „,tragische Lebensgefühl“ sei es mehr nietzscheistischer oder heideggerscher Art“, meint 1946 der Direktor des Innsbrucker Institut Français Maurice Besset, und somit letztlich eine „Sehnsucht nach Selbstverwirklichung “138. Vielen existentialistischen HeldInnen gleichend, sprechen aus den von Jelinek gezeichneten „verschwommenen Existenzen“ Einsamkeit, Hass, Ekel, Verzweiflung, Hoffnungslosigkeit, „Berge der Angst" ${ }^{139}$ und Verachtung. Sie halten das Ideal eines extremen Individualismus aufrecht unter Berufung auf den Existentialismus als eines jener „Zaubersysteme, mit denen man im Westen die Einsamkeit der Individuen in eine Form

136 Jelinek: Die Ausgesperrten, S. 229. Diese einzige mit einem politischen Bewusstsein ausgestattete Figur spiegelt nach Dagmar C. G. Lorenz „the author’s own ideological predicament“, auch wenn Jelinek auf fiktionalem Boden ihre „dissatisfaction with any existing socialist society“ in der Aussichtslosigkeit von Frau Sepps Anliegen lächerlich macht. Lorenz: Elfriede Jelinek’s Political Feminism: Die Ausgesperrten. In: Modern Austrian Literature 23 (1990), Nr. 3/ 4, S. 111-119, hier S. 114, 115. Zu Jelineks KPÖ-Mitgliedschaft zur Zeit des Verfassens von Die Ausgesperrten cf. das Interview: Der Mensch ist eine Ratte. In: Sichrovsky (Hg.): Einblicke. Begegnungen und Porträts. Wien 1990, S. 181-187.

137 Sartre: Autoportrait à soixante-dix ans, S. 180.

138 Maurice Besset: Jugend und Literatur in Frankreich. In: Plan 1 (1946), Nr. 11, S. 920-925, hier S. 924.

139 Jelinek: Die Ausgesperrten, S. 215, 243; cf. S. 153. 
von Heldentum umdeutet" ${ }^{\text {“140 }}$, wie Franz Schuh einmal formuliert. Die Charakterisierung der Figur Rainer - „Es ist ein Heroismus in ihm, der einsam ist“: „Er verabscheut nämlich die Masse und ragt deshalb deutlich über sie hinaus" ${ }^{\text {“141 }}$ - tendiert dabei in Richtung eines Nietzscheanischen Überlegenheitsgestus (im Sinne von „[m]an muß der Menschheit überlegen sein durch Kraft, durch $\mathrm{H}$ ö he der Seele, - durch Verachtung ... “142); mehr noch verleiht Rainer seinem Existentialismus sozialdarwinistische Züge, wenn er, als Stärkerer, sich gegen die „Gleichheit aller“ positioniert, „die ja gegen die Natur und deren Vererbungslehre wäre“143. Die Witkowski-Zwillinge wähnen sich schließlich „überlegen im Unglück, weil sie sich von allem frei gemacht haben und tun was sie wollen. Rainer sagt, die Menschen sind schon irgendwie determiniert, aber ich nicht, weil ich ihnen überlegen bin, auf Grund meines Willens. “144 Durch diese Reaktion auf ihre allseitige Bestimmt- und Bedingtheit - durch Eltern, Schule, das soziale Umfeld - verkörpern sie für Sichrovsky die „Tragödie des intellektuellen Kleinbürgertums in seinem manischen Geltungsbedürfnis“" ${ }^{\text {145; }}$; sie können sich letztlich ebenso wenig von ihrem Milieu lösen wie ihr Vater die im Krieg eingespielten Verhaltensmuster ablegen kann. In diesem Sinne destruiert Jelinek laut Janz nicht nur „den existentialistischen Mythos vom freien ,Selbstentwurf" des Einzelnen“, sondern liefert auch „eine böse Parodie auf den bürgerlichen Bildungsroman mit seiner Utopie der freien Entfaltung des Individuums bei gleichzeitiger Integration in die Gesellschaft.“146

Bei Jelineks Figuren ist das Gefühl der Auserwähltheit eng mit dem der Ausgeschlossenheit verbunden. Die Handlung von Die Ausgesperrten trägt sich 1959 zu, dem Publikationsjahr von Sartres Les Séquestrés d'Altona, das 1960 als Die Eingeschlossenen bei Rowohlt erscheint und am 4. September 1960 im Wiener Volkstheater unter der Regie von Leon Epp als österreichische Erstaufführung

140 Franz Schuh: Lest Sartre! In: Profil, 21.04.1980.

141 Jelinek: Die Ausgesperrten, S. 34, 128.

142 Friedrich Nietzsche: Der Antichrist. Fluch auf das Christenthum. In: Nietzsche: Sämtliche Werke. Kritische Studienausgabe in 15 Bänden (KSA), Bd. 6. Hg. von Giorgio Colli und Mazzino Montinari. München 1999, S. 167-168, hier S. 168 (Hervorhebung im Original).

143 Jelinek: Die Ausgesperrten, S. 55.

144 Jelinek: Die Ausgesperrten, S. 34.

145 Heinz Sichrovsky: Die Ausgesperrten. In: Arbeiter-Zeitung, 17.11.1979.

146 Janz: Elfriede Jelinek, S. 52, 44. Als weitere Denksysteme, die durch Jelinek eine ähnlich zerstörerische Behandlung erfahren, nennt Janz „den marxistischen Mythos von der Arbeiterschaft als revolutionärem Subjekt und den feministischen Mythos von den Frauen als ,subversivem" Potential.“ 
Premiere feiert. ${ }^{147}$ In dem Stück über die Hamburger Industriellenfamilie Gerlach, über die seit Kriegsende der laut Todeszertifikat in Argentinien verstorbene, in Wirklichkeit aber in seinem Zimmer versteckte Sohn Frantz herrscht, ist man ebenso eingeengt („drôlement coincés“148) wie bei den Witkowskis, die sich „in ein auswegloses Gefängnis eingesperrt“"149 fühlen. Über den auffälligen Titel hinaus enthält Die Ausgesperrten diverse thematische Reminiszenzen (der Umgang mit Schuld, der Generationenkonflikt, die zu enge Geschwisterbindung) zu dem Stück, auch sehr spezifische, als etwa Rainer wie Sartres Figur Frantz Gerlach versucht, sich und seinen Vater mit dem Auto in den Tod zu stürzen. Dass Rainer schließlich seine ganze Familie auslöscht, mit dem Gesichtsausdruck eines Menschen, „der Camus liest und aus Quälerei an der Welt ans Töten schreiten muß ${ }^{\text {“150 }}$, erteilt sowohl dem Absurdismus als auch dem Existentialismus als positive philosophische Vorbilder eine letzte drastische Absage.

Rainer, der seine Lage „zahllosen Teenagern seiner Generation“ gleich als „aussichtslos“151 beschreibt, übertrifft mit seiner Tat alle Schreckensvisionen vom berüchtigten Sartreschen „Idealismus der Ausweglosigkeit“152. Dass das seelische Vakuum einer Generation ohne Eigenschaften (die Namen Sophie Pachhofen und Hans Sepp stammen von Musil) emphatisch mit dem Existentialismus befüllt werden kann, wird andererseits darauf zurückgeführt, dass Sartre die Jugend optimistisch sein lässt in einer zu Pessimismus ausreichend Anlass bietenden Welt; gerade dies macht Sartres Denken für Günther Nenning

147 Das Volkstheater bringt im Vorjahr 1959 bereits die österreichische Erstaufführung von Sartres Das Spiel ist aus, unter der Regie von Gustav Manker, dem Vater von Paulus Manker, der in der Verfilmung von Jelineks Die Ausgesperrten 1982 die Figur des Rainer Witkowski spielen wird. 148 Jean-Paul Sartre: Les Séquestrés d’Altona. In: Sartre: Théâtre complet, S. 857-993, hier S. 957. 149 Jelinek: Die Ausgesperrten, S. 167. Eine besondere Nähe zu diesem Sartre-Stück (sowie zu Huis clos) lassen auch Thomas Bernhards Dreiecks-Dramen Ritter, Dene, Voss (1986) und Vor dem Ruhestand (1979) erkennen, unter anderem in den Unaufrichtigkeiten, den gegenseitigen Unterwerfungen und Erstarrungen ihrer Hauptfiguren.

150 Jelinek: Die Ausgesperrten, S. 206. Cf. auch Heidi Strobel: Gewalt von Jugendlichen als Symptom gesellschaftlicher Krisen. Literarische Gewaltdarstellungen in Elfriede Jelineks „Die Ausgesperrten“ und in ausgewählten Jugendromanen der neunziger Jahre. (Europäische Hochschulschriften I/1655.) Frankfurt am Main 1998.

151 Jelinek: Die Ausgesperrten, S. $164 \mathrm{f}$.

152 Rudolf Jeremias Kreutz: Oesterreichs Jugend. In: Europäische Rundschau 3 (1948), Nr. 18, S. 832-835, hier S. 834. 
zu einem „Meisterstück“153. Schon die sogenannte Stunde Null stellt mentalitätsgeschichtlich eine ,von extrem gegensätzlichen Stimmungen geprägte Bedürfnislage“154 zwischen Verzweiflung und Aufbruchsgefühl dar, in der man mit dem Existentialismus ,zugleich den Sinn des Lebens radikal in Zweifel ziehen und dabei doch ein entschieden lebensbejahendes Engagement bezeugen konnte. “155 Nach der Geistesverfassung der österreichischen Nachkriegsjugend gefragt, antwortet Otto Basil, „optimistisch sehen diese Zwanzigjährigen nicht in die Zukunft, die ihnen gehören soll“"156, doch seien sie weniger unpolitisch und individualistisch als in der Öffentlichkeit dargestellt. Der aus Oberösterreich stammende Autor und Kritiker Herbert Eisenreich relativiert ebenfalls, dass es „eine zwar illusionslose, nicht aber eine nihilistische Generation ist; eine skeptische, nicht aber eine ungläubige; eine autoritätsfeindliche, nicht aber eine anarchistische.“"157 Zum Mindesten sei die „intellektuelle Jugend von heute von einer tiefen Skepsis gegen alle ihr vermittelten Werte erfüllt“"158: Nationalsozialismus und Krieg haben die Identifikationsbereitschaft mit bestimmten politischen Systemen und Ideologien erschüttert. ${ }^{159}$ Entsprechend hängt auch der Ruf Sartres davon ab, ob er als „Destrukteur der bürgerlichen Ideologien“160 und damit als Leitrebell gegen das elterliche Milieu befürwortet oder durch seinen „geradezu nihilistischen Skeptizismus“161 selbst als Ideologe abgelehnt wird.

153 Nenning: Sankt Sartre, S. 22.

154 Rahner: Jean-Paul Sartre als Modell des Intellektuellen, S. 321.

155 Werner: Vorwort. In: Rahner: Die Rezeption des französischen Existentialismus im kulturellen Feld Westdeutschlands, S. 8.

156 Otto Basil: Stimme der Jugend. In: Plan 1 (1946), Nr. 4, S. 307-310, hier S. 307.

157 Herbert Eisenreich: Das schöpferische Mißtrauen oder Ist Österreichs Literatur eine österreichische Literatur? (1959). In: Eisenreich: Reaktionen. Essays zur Literatur (1964), S. 72-104, hier S. 83.

158 Rudolf Lind: Was sollen wir tun? In: Plan 1 (1946), Nr. 7, S. 558-562, hier S. 560 f.

159 Cf. Schelsky: Die skeptische Generation, S. 85.

160 Améry: In die Welt geworfen, S. 196.

161 Kreutz: Oesterreichs Jugend, S. 834. Mannheim definiert: „Als Ideologien legt man gegnerische Ansichten erst aus, wenn man sie nicht einfach als erlogen erlebt, sondern in der ganzen Haltung eine Unwahrhaftigkeit wittert, die man als Funktion einer sozialen Lagerung deutet.“ Karl Mannheim: Ideologie und Utopie. (Schriften zur Philosophie und Soziologie 2.) Bonn 1929, S. 14. Für Sartre ist es erst die Verfestigung, die die Ideologie zur Unaufrichtigkeit werden lässt. Selbst der Meinung, dass Ideologien im Moment des Entstehens Freiheit seien, im Moment der Verfestigung jedoch Unterdrückung (,les idéologies sont liberté quand elles se font, oppression quand elles sont faites“ [Qu'est-ce que la littérature?, S. 161]), übt Sartre in seiner Prosa Ideologiekritik, am deutlichsten in der Erzählung L'Enfance d'un chef (Paris 1939, S. 48, 104, 49): Die jugendliche Hauptfigur Lucien Fleurier sucht darin nach Orientierung und Halt und wird fündig in der Psychoanalyse, die ihm als Offenbarung (,une révélation“) erscheint, bevor er sich auf Anraten neuer Freunde plötzlich durch den Antisemitismus definiert 
Steht die Mentalität nach 1945 im Zeichen der „Diskreditierung der Ideologien“162, gilt dies laut Eisenreich für die ÖsterreicherInnen noch besonders, da Ideologieskepsis ohnehin $\mathrm{zu}$ den (nur vorübergehend außer Kraft gesetzten) „simplen Fundamenten österreichischer Wesensart“ gehöre, neben „Skepsis gegenüber dem Erfolg, Mißtrauen gegen den Fortschritt, Zweifel an der Wichtigkeit gerade dessen, was allgemein für wichtig gilt“163. Man sei, fügt Hans Heinz Hahnl hinzu, bereits durch die eigene Grundverfassung auf das „Ich seiner existentiellen Verlorenheit und Verlassenheit“ geworfen, auch ohne Hilfe aus Paris: „Die jungen Österreicher kamen auch ohne Sartre und Camus auf diese Verhaltensmuster und fanden sich, wenn sie die Existentialisten lasen, nur in ihren Lebenserfahrungen und dem von ihren Lebenserfahrungen aufgedrängten Rückweg ins Ich bestätigt.“164

Sie lesen sie dennoch, wie viele Erinnerungen österreichischer SchriftstellerInnen belegen, auch in den nachfolgenden Jahrzehnten. Dass sich der Existentialismus über die Philosophie hinaus als Stil einer Epoche, als globale Reaktion auf eine historische Situation (,un style d'époque, l'expression globale de réactions à une situation historique ${ }^{\text {“165 }}$ ) manifestiert, bedeutet nicht, dass er an diese Situation gebunden ist, wie wiederkehrende Rufe nach einem Neoexistentialismus (zu dessen theoretischer Verfestigung es indes nie kommt) zeigen. Wegen des diachronen Charakters von Transferprozessen existiert zwar grundsätzlich „keine temporale Symmetrie“166, doch liegen beim Existentialismus zwischen dem Entstehungskontext in der Besatzungszeit und den (fortlaufenden) Rezeptionskontexten bald viele Jahrzehnte. Der Erwartungshorizont des jugendlichen Publikums scheint sich im Verlauf dieser Dauerrezeption nicht sonderlich zu ändern, die provokative Kraft von Sartres und Camus' Literatur hält auch im 21. Jahrhundert an, in dem sie längst zu Schulklassikern kanonisiert sind.

33 Jahre nach Jelineks Die Ausgesperrten erscheint 2013 mit Norbert Gstreins Eine Ahnung vom Anfang neuerlich ein Werk, in dem existentialistisches Gedankengut in Verdacht gerät, geneigte SchülerInnen auf Abwege zu bringen, nun in

und schätzt („une méthode pour se définir et s'apprécier“) und sich von ihm ein Wesen und ein Schicksal („un caractère et un destin“) verleihen lässt.

162 Hans Heinz Hahnl: Von der Diskreditierung der Ideologien. Erwartungshaltungen und literarische Produktion nach 1945. In: Waechter-Böhm (Hg.): Wien 1945. davor/danach. Wien 1985, S. 153-163, hier S. 157.

163 Herbert Eisenreich: Worin besteht der Unterschied? Ein Vergleich zwischen der jungen Literatur Österreichs und Deutschlands. In: FORVM 1 (1954), Nr. 7/8, S. 34-36, hier S. 35.

164 Hahnl: Von der Diskreditierung der Ideologien, S. 157.

165 Dugast: La Situation culturelle de la France après 1945, S. 312.

166 Werner: Dissymmetrien und symmetrische Modellbildungen in der Forschung zum Kulturtransfer, S. $89 \mathrm{f}$. 
den neunziger Jahren und in ländlicher Gegend. Der Deutschlehrer Anton berichtet von einem Sommer, den er mit seinem ehemaligen Schüler Daniel und dessen Freund in einem Waldhaus verbringt. Ein als Existentialismus-Vermittler agierender Pädagoge ist auch außerliterarisch kein ungewöhnliches Vorkommnis, wie unter anderem das Erweckungserlebnis des fünfzehnjährigen Josef Winkler nahelegt: Er „hatte im Bücherregal unserer Lehrerin, der Stoxreiter Waltraud, ,Die Pest" von Camus gefunden und [sich] ausborgen dürfen und spätestens beim Lesen dieses Buches gewußt, daß [er sich] von nun an mit Literatur beschäftigen würde“167. Gstreins Held empfiehlt seinen Schützlingen ebenfalls (den hier in die weitere Existentialismus-Sphäre inkludierten) Camus, konkret den Roman Der Fremde, sieht sich jedoch schnell in der Situation, diesen Lektüre-Ratschlag rechtfertigen zu müssen, nachdem eine Bombendrohung die dörfliche Stasis aufbricht und den unangepassten Lehrer und seinen widerspenstigen Schüler ins Zentrum der Aufmerksamkeit rückt. Anton insistiert: „Der Fremde galt nun wahrlich nicht als Geheimtip, auch bei uns in der Provinz nicht“"168. Zu weiterem Unmut führen Theaterproben von Camus' Die Gerechten, ein Stück über sozialistische Revolutionäre im zaristischen Russland während der Unruhen von 1905, vom Elternverein seiner „aufrührerischen Ideen“ wegen („kommunistische Umtriebe und Aufruf zur Gewalt“"169) sabotiert.

Von diesem Stück, Les Justes (1949), erfährt das österreichische Publikum erstmals 1950 in der Besatzungspresse: Es sei im Gegensatz zum Vorgänger Belagerungszustand (L'État de siège, 1948), welches Publikum und KritikerInnen in Frankreich enttäuscht habe, weil es ,abstrakt, unlebendig, ja stellenweise langweilig“ gewesen sei, nun „ein gut gebautes, spannendes Stück“"170. Die erste größere Inszenierung von Die Gerechten im Wiener Volkstheater im März 1951 (Regie: Gustav Manker) muss dennoch nach drei Vorstellungen abgesetzt werden, zu extrem erscheint der Inhalt. An Aktualität verliert die Frage, inwieweit Gewalt legitim sein kann, um noch größere Gewalt zu verhindern, allerdings nicht, wie eine Rezension

167 Josef Winkler: Winnetou, Abel und ich. Mit Bildern von Sascha Schneider. Berlin 2014, S. 51.

168 Gstrein: Eine Ahnung vom Anfang, S. 96. Die im Roman vorherrschende Präferenz für Albert Camus thematisiert eine Schülerin, die meint, „im Streit zwischen Camus und Sartre müsse man sich nur Fotos von ihnen ansehen, um zu wissen, dass Camus recht gehabt habe, oder um sich zumindest genau das zu wünschen“ (S. 277 f.), und die damit das berühmte Diktum ,Lieber mit Sartre irren als mit Aron recht haben` zu ,Lieber mit Camus irren als mit Sartre recht haben' variiert.

169 Gstrein: Eine Ahnung vom Anfang, S. 97, 191. Cf. auch Marie Gunreben: Die Gefährlichkeit der Literatur. Norbert Gstreins Roman „Eine Ahnung vom Anfang“. In: Text + Kritik 2015, Nr. 15 (Sonderband: „Österreichische Gegenwartsliteratur“), S. 164-174.

170 o. V.: „Die Gerechten“ von Albert Camus. In: Geistiges Frankreich, 16.01.1950. 
zur Aufführung einer Collage nach Les Justes, „Monsieur Camus oder Die vergessene Revolte“, Anfang der achtziger Jahre im Wiener Dramatischen Zentrum zeigt:

Seit vielen Jahren hat es sich in der Wiener Theaterszene nicht mehr derart nachdrücklich gerührt. [...] Menschen im Gewissenskonflikt zwischen zweierlei Humanismus: Der eine rechtfertigt Mord und Gewalt als Mittel des Kampfes gegen Mord und Gewalt von ungleich größerem Ausmaß, der andere hemmt die Hand, die gegen den Kopf eines Menschen abdrücken will. ${ }^{171}$

In Gstreins Roman erträgt Held Anton das in seinen Augen vollkommen harmlose Stück durch „seine hochtrabende Thesenhaftigkeit“ („ein einziges Wahrheits- und Wahrhaftigkeitsgetöse über Freiheit und Gerechtigkeit“"172) zwar kaum, unterstützt es aber aus Prinzip. Im Gegensatz zu diesem Drama sei Camus’ im Band Das Exil und das Reich zu findende Erzählung „Der Abtrünnige“ über einen wahnsinnig werdenen Missionar in Bezug auf die gegenwärtigen Verhältnisse „erschreckend hellsichtig“173, schaltet sich der wohlgesinnte Schuldirektor ein. Jeder ziehe sein Tun in Zweifel, beruhigt er, „das Entscheidende sei, ob man weitermache, obwohl einem plötzlich alles als sinnlos erscheine“174, womit er die von Camus in Le Mythe des Sisyphe aufgeworfene Frage nach der adäquaten Reaktion auf den Einbruch des Absurden paraphrasiert (cf. Kap. 6.3). Während Anton im Einverständnis mit dem provokanten Satz, der Camus' Essay beschließt - man müsse sich Sisyphos glücklich vorstellen (,[i]l faut imaginer Sisyphe heureux““175) - , mit seinem Leben fortfährt, hat sein Bruder vor langer Zeit das seine beendet. Dessen Lieblingsbuch, Der Fremde, gehört laut Anton letztlich doch zu den Werken, die das (wenn auch selten entfaltete) Potential hätten, „für einen normalen Alltag untauglich zu machen“, und die er nun seinem Schüler Daniel anbietet, „als sollten sie wieder eine Antwort geben, die sie schon einmal nicht hatten geben können“"176.

171 Heinz Sichrovsky: Rechtfertigung der Gewalt? In: Arbeiter-Zeitung, 01.04.1982.

172 Gstrein: Eine Ahnung vom Anfang, S. 191.

173 Gstrein: Eine Ahnung vom Anfang, S. $97 \mathrm{f}$.

174 Gstrein: Eine Ahnung vom Anfang, S. 85.

175 Albert Camus: Le Mythe de Sisyphe. Paris 1942, S. 168. Cf. Gstrein: Eine Ahnung vom Anfang, S. 24: „[T]atsächlich war ich nach den Monaten im Klassenzimmer so zufrieden mit der Arbeit im Freien und ihrer Ziel- und scheinbaren Nutzlosigkeit, dass ich zum ersten Mal den Satz zu begreifen glaubte, nach dem man sich Sisyphos als glücklichen Menschen vorzustellen habe, weil ich mich bei dem Wunsch ertappte, jemand möge hinter mir alles rückgängig machen.“

176 Gstrein: Eine Ahnung vom Anfang, S. 45, 52. Im Interview mit Bettina Steiner betont Gstrein (Die gefährliche Lust, recht zu haben. In: Die Presse, 11.08.2013) diesbezüglich, das Problem sei „nicht die Literatur selbst, sondern der jugendliche Leser mit seinen Idealvorstellungen“. Zur Bedeutung Camus' für den Autor cf. Norbert Gstrein und Stefan Zweifel: Zweifels Reflektorium, 
Die „Unbedingtheit, mit der er die Dinge ernst genommen habe“ unterscheidet Daniel in den Augen seines Lehrers von seinen MitschülerInnen. Seien der jugendliche Defätismus einerseits, „der nackte, ungeschützte Idealismus“ andererseits sonst vorübergehende Phänomene, falle auf, dass Daniel, während ,andere ihre Ausflüge ins Existentialistische belächelten und froh Bestand aufnahmen, dass sie waren, was sie waren, und hatten, was sie hatten, sich immer mehr darin verbiss. “177 Mit ihm ist neuerlich ein Jugendlicher porträtiert, bei dem die Existentialismus-Aufnahme eskaliert, wenn auch in geringerem Maß als bei Jelineks Rainer Witkowski. Die Helden eint mehr: Schätzt Anton im Grunde Daniels „Hang zum Paradoxen, zum Wortspielerischen, zum scheinphilosophischen Tiefsinn“, bezeichnet der Schuldirektor ihn als „Hochstapler“ und benennt unumwunden, was ihn stört: „der metaphysische Schleim, mit dem er alles überzieht““178. Einschätzungen zu Rainer, aus dem nur „verbaler Durchfall“"179 herauskomme, klingen ähnlich. Die (Pseudo-)Intellektualität wird durch Unaufrichtigkeit in materieller Hinsicht ergänzt: Schon dass bei den philosophisch legitimierten actes gratuits den pekuniären Reizen schwer zu widerstehen ist, lässt Misstrauen an Rainers Integrität aufkommen, bei späterer Gelegenheit prahlt er offen mit dem (imaginierten) Sportauto seines Vaters, wie auch die Figur Daniel den absenten Vater als Lebemann mit teurem Wagen ausgibt. Infrage gestellt wird damit auch die den ExistentialistInnen zugeschriebene konsumkritische Haltung als eines jener Klischees, die das wirkungsgeschichtliche Gewebe durchziehen. Dass die existentialistische Subkultur als dem Konsum abgeneigt und „[d]istanziert gegenüber dem american way of life“180 gilt, lässt sich an Jelineks Jugendlichen nicht ablesen, wobei der Arbeiter Hans am offensten zugibt, dass viel Ersehntes aus den Vereinigten Staaten stammt (,die Bluejeans und sämtliche heiße Musik“181). Die Ausgesperrten illustriert mit diesen sich scheinbar widersprechenden Vorlieben, was wenige Jahre zuvor durch den Besatzungskontext die Begegnung mit dem Existentialismus zu einem Spezialfall macht: trianguläre Transferprozesse zwischen Österreich, den USA und Frankreich, bei denen sich kulturelle Güter wie der Jazz, amerikanische Literatur und

Folge 31 („Über seinen neuen Roman und 100 Jahre Camus“). http://www.burgtheater.at/Con tent.Node2/home/ueber_uns/aktuelles/Reflektorium31.at.php (einges. 12.12.2015).

177 Gstrein: Eine Ahnung vom Anfang, S. 20, 57, $49 \mathrm{f}$.

178 Gstrein: Eine Ahnung vom Anfang, S. 49, 95, 89.

179 Jelinek: Die Ausgesperrten, S. 239.

180 Dietmar Hüser: Amerikanisches in Deutschland und Frankreich - Vergleich, Transfer und Verflechtung populärer Musik in den 1950er und 1960er Jahren. In: Lüsebrink und Oster (Hg.): Am Wendepunkt, S. 283-305, hier S. 299.

181 Jelinek: Die Ausgesperrten, S. 228. 
Hollywoodfilme über die Grenzen von Hoch- und Massenkultur hinweg mit der Strömung verbinden.

Zwar ist je nach Zone der unmittelbare Einfluss der zuständigen Alliierten stark, auf Bundesebene überwiegen allerdings Importe aus den USA. Bei der Amerikanisierung des kulturellen Feldes - stets „bei parallelem ,inhaltlichen“ Rekurs auf Tradition und ,Erbe“, ,Schönheit“ und ,Wahrheit““'182- ist wenig dem Zufall überlassen. Auch wenn sich nach der Kulturtransfertheorie die Übernahme fremder Elemente „nicht dekretieren oder durch eine gezielte Expansionspolitik der Ausgangskultur erreichen"183 lässt, zeigt dieses Beispiel, welchen Effekt ein entsprechendes Nachhelfen haben kann. Wie die französischen Kulturverantwortlichen gehen die amerikanischen davon aus, dass sie die größte Wirkung erzielen, indem sie „vorhandene österreichische Vorstellungsmuster verstärken“, weshalb der zuständige Information Services Branch „möglichst friktionsfreie, idealisierende Bücher, Filme und Musikstücke“ propagiert und einen (im Gegensatz zu den eher undifferenzierten Initiativen der anderen Besatzungsmächte) auf „ganz bestimmte Zielgruppen ausgerichteten Operationskalender“ entwirft, der medienübergreifend „,vor allem die Hochkultur sowie moderne Unterhaltungs- und Massenbeeinflussungsinstrumente“184 umfasst, wie Oliver Rathkolb hervorhebt.

Als ergiebigsten Werbeträger nutzen die USA den Film, der eine Vermittlung sowohl ihrer demokratischen Ideale als auch indirekt ihrer materiellen Güter ermöglicht. Deutlich vernehmbar sind die Stimmen, die darin eine Gefahr für die Jugend sehen, die bald im Ruf steht, „daß sich ihr Dasein nur im materiellen Ablauf erschöpft, daß sie sich an gänzlich unwichtige Dinge verschwendet, massenweise Gangster- und Kriminalfilme besucht, bornierte Liebesgeschichten verschlingt“185 und sich so in den geistigen Bankrott katapultiert. Die Faszination, die Kinohelden wie Marlon Brando und James Dean ausüben, greifen viele Texte, die die Nachkriegszeit aus jugendlicher Perspektive schildern, auf: Statt zur Schule geht Josef Winkler „oft schon um zehn Uhr vormittags ins Apollokino am Ufer der Drau“, zusammen mit „den anderen Beatles, Hippies und Schulschwänzern aus den Villacher Gymnasien, der Handelsschule und

182 Georg Schmid: Die „Falschen“ Fuffziger. Kulturpolitische Tendenzen der fünfziger Jahre. In: Aspetsberger, Frei und Lengauer (Hg.): Literatur der Nachkriegszeit, S. 7-23, hier S. 23.

183 Espagne und Greiling: Frankreichfreunde, S. 10.

184 Rathkolb: Die Entwicklung der US-Besatzungskulturpolitik, S. 38, 45f., 35. Cf. auch Alfred Hiller: Amerikanische Medien- und Schulpolitik in Österreich 1945-1950. Wien: Universität Wien, Diss. 1974.

185 Thomas Bernhard: Die Kultur ist nicht stehen geblieben! In: Bernhard: Werke, Bd. 22/1, S. 141-144, hier S. 141. [Zuerst in: Demokratisches Volksblatt, 04.04.1953.] 
Handelsakademie“186. Gernot Wolfgruber hat sich, so wie sich der Lehrling in seinem Roman Auf freiem Fuß (1975) „fast täglich ins Kino“187 begibt, in die Welt auf der Leinwand „hineingewünscht“"188. Das in den Filmen präsentierte andere Leben weckt Träume, die an den starren Strukturen der Wirklichkeit zerbrechen, am „Wertesystem einer rückwärtsgewandten und restriktiven Gesellschaft“, lautet die Diagnose von Robert Buchschwenter, der hier keinen Raum für ein haltbares „alternatives kulturelles Narrativ“ sieht: Es ist die „transzendente Erfahrung, die einem amerikanische Kult-Filme bescherten, so völlig abgelöst von sozialen Realitäten österreichischer Jugendlicher, dass sie selten mehr als einen unmittelbaren Ausbruch an gegenstandsloser Gewalt oder folgenloser Begeisterung zur Folge hatten“189.

Doch stellt der Hollywoodfilm nur einen Teilbereich dessen dar, was dem Nachkriegspublikum an die ,abgebrochene Moderne“ anzuknüpfen erlaubt: Es ist, schreibt Heinrich Deisl, „für die 1950er prägend, dass Sartre/Camus und Jazz, Baudelaire/Villon und Boogie Woogie, The Wild One und Moderne Kunst eine, wenn auch desperate Einheit ergaben“190. Die Einheit erscheint zumindest weniger disparat, wenn man den Existentialismus als bereits stark von der amerikanischen Literatur und Musik beeinflusst denkt; auch von Hollywood, mit dessen wesentlichen Erzeugnissen („l'essentiel de l'histoire du cinéma“"191) Beauvoir und Sartre seit Beginn der 1930er Jahre vertraut sind. In Ermangelung akzeptabler nationaler Produktionen (,rien d'acceptable“) ist die Nachfrage der französischen Bevölkerung nach 1945 beträchtlich, berichtet Beauvoir, die sich viel („monts et merveilles“192) vom amerikanischen Film verspricht, der wie die Literatur nicht nur Unterhaltung und Kunst (,un divertissement et un art“) für sie und Sartre darstellt, sondern die Erweckung einer Welt („une évocation du monde“193).

Beauvoir beschreibt in ihrer Autobiographie La Force des choses, wie die amerikanische Kultur - Jazz, Kino, Literatur - als etwas Unerreichbares, als ein großer Mythos ihre Jugend bestimmt (,[ç]a signifiait tant de choses, l’Amérique! Et d'abord, l'inaccessible; jazz, cinéma, littérature, elle avait nourri notre

186 Winkler: Winnetou, Abel und ich, S. $29 \mathrm{f}$.

187 Gernot Wolfgruber: Auf freiem Fuß. Salzburg ${ }^{6} 1988$, S. 35.

188 Hoffmeister: Access Routes into Postmodernism: Interviews with Innerhofer, Jelinek, Rosei, and Wolfgruber. In: Modern Austrian Literature 20 (1987), Nr. 2, S. 97-130, hier S. 129.

189 Robert Buchschwenter: „Johnny, ein Glas Milch!“ Kino, Pop und der Kampf um den (guten) Geschmack. In: Horak et al. (Hg.): Randzone, S. 103-125, hier S. 123, 122.

190 Deisl: Im Puls der Nacht, S. 21.

191 Emmanuel Leclercq: Le Cinéma selon Simone de Beauvoir: les visages et les mythes. In: Les Temps modernes 2002, Nr. 619 [Juni-Juli], S. 185-248, hier S. 185.

192 Beauvoir: La Force des choses, Bd. 1, S. 26.

193 Leclercq: Le Cinéma selon Simone de Beauvoir, S. 187. 
jeunesse mais aussi elle avait été un grand mythe: un mythe ne se laisse pas toucher“194). Dieser Mythos rückt nach der Befreiung Frankreichs in greifbare Nähe. Im französischen Alltag ist durch Konsum- und Kulturgüter die Macht, die die Vereinigten Staaten politisch, wirtschaftlich und kulturell auf Europa ausüben, deutlich spürbar. Die anfängliche Glorifizierung der amerikanischen Armee als heroische und großzügige BefreierInnen aus dem Land der Demokratie weicht wachsenden Vorbehalten gegen die Rassismus und soziale Ungleichheit umfassende Schattenseite der glänzenden Kulisse, so Dugast, ${ }^{195}$ weshalb eine antiamerikanische Haltung in Frankreich bald weit über kommunistische Kreise hinausreicht. Raymond Aron bestätigt in einer Sammlung von heterostereotypen Bildern, As Others See Us. The United States through Foreign Eyes, die Amerikanisierung sei „looked upon by many with horror“, das Land verursache „mixed feelings - envy and resentment combined with admiration or fear“196. Während die Zweiteilung der Welt voranschreitet, sträubt sich Frankreich in seinem Selbstverständnis als Kulturnation gegen den als bedrohlich empfundenen Kulturimperialismus, deutet Michel Winock; es geschehe dies aus Furcht, in den Vereinigten Staaten die eigene Zukunft zu erblicken („nous la craignons parce qu'elle est en nous, parce qu'elle est une des virtualités à haute probabilité de notre avenir“197). Eben weil sie sie als im Gange befindliche Zukunft („l'avenir en marche“198) auffassen, bewahren Sartre und Beauvoir trotz ihres antikapitalistischen Standpunkts Interesse an der Kultur der Vereinigten Staaten. Durch ihre ersten USA-Aufhalte in den Jahren 1945, 1946 und 1947 bewahrheiten sich einige von Sartres, Camus' und Beauvoirs Annahmen, andere erscheinen in neuem Licht. So würdigt Sartre in seinem kurzen Text „Nick’s Bar, New York City“ (1947) den Jazz als die Nationalunterhaltung („le

194 Beauvoir: La Force des choses, Bd. 1, S. 32.

195 Cf. Dugast: La Situation culturelle de la France après 1945, S. 309. Cf. auch Frank Costigliola: France and the United States. The Cold Alliance Since World War II. New York 1992.

196 Raymond Aron: From France. Englisch von Anita Tenzer. In: Joseph (Hg.): As Others See Us. The United States through Foreign Eyes. Princeton 1959, S. 57-71, hier S. 60.

197 Michel Winock: Nationalisme, Antisémitisme et Fascisme en France. Paris 1990, S. 51.

198 Beauvoir: La Force des choses, Bd. 1, S. 32. Vor ihren ersten transatlantischen Reisen erhalten Sartre und Beauvoir von FreundInnen und Bekannten Einblicke in das amerikanische Leben, vom Journalisten Jacques-Laurent Bost, dem surrealistischen Schriftsteller und Journalisten Philippe Soupault, von Beauvoirs Vertrauter Nathalie Sorokine, die mit dem in Frankreich stationierten späteren Drehbuchautor Ivan Moffat im Februar 1946 nach Kalifornien übersiedelt, wo auch Henriette Nizan bis Ende des Krieges in der Filmbranche arbeitet, sowie von Stépha und Fernando Gerassi, die nach New York emigrieren, wo sich auch der für die Relations culturelles tätige Bekannte Claude Lévi-Strauss aufhält. 
divertissement national des États-Unis“(199), nachdem er bereits in den zwanziger Jahren den Internationalismus (,[i]nternationalisme“200) dieser seine eigene Epoche kennzeichnenden Musikrichtung betont hat. Durch die Universalität des transnationalen Idioms hat sich in der Zwischenzeit der amerikanische Jazz mit dem französischen Existentialismus amalgamieren können, um dann als Einheit „Jazz und Sartre“201 im deutschsprachigen Raum rezipiert zu werden, zugleich mit dem von der US-Besatzung angeregten (und von der sowjetrussischen als „decadent and alien“202 angesehenen) Jazz-Import.

Der Jazz ist integraler Bestandteil des Sartreschen auf Mode und Lebensstil ausgedehnten Metafeldes. Während die Kerngruppe der philosophisch-literarischen Strömung überschaubar ist, gibt es einen beträchtlichen „Kreis von Sympathisanten und Nachahmern“, deren Engagement für die Sache sich vielfach auf „die Übernahme des äußeren Habitus oder eine allgemeine Begeisterung für die Jazzmusik reduzierte. “203 Der Jazz scheint der kleinste gemeinsame Nenner, wie Stephan Braese für den bundesdeutschen Kontext festhält: Um zur Jugendbewegung zu werden, „bedurfte es der Flankierung durch eine französische JazzSzene, die - gleichsam als Verstärker - tatsächliche oder auch nur vermeintliche Merkmale des Existentialismus überzeugend in sich aufnahm und verbreitete.“204 Konfrontiert mit dem Resultat muss Jean Améry sich wundern, wieso „echte und falsche Studentlein, welche Metaphysik und Be-Bop verwechselten, sich als

199 Jean-Paul Sartre: Nick’s Bar, New York City. In: Contat und Rybalka (Hg.): Les Écrits de Sartre, S. 680-682, hier S. 682. [Zuerst in: America, 1947, Nr. 5 (Jazz 47).]

200 Jean-Paul Sartre: Fragment sur le jazz. In: Contat und Rybalka (Hg.): Écrits de jeunesse. Paris 1990, S. 357-361, hier S. 360. Cf. Dina Gusejnova: Jazz Anxiety and the European Fear of Cultural Change: Towards a Transnational History of a Political Emotion. In: Cultural History 5 (2016), Nr. 1, S. 26-50.

201 Deisl: Im Puls der Nacht, S. 16.

202 Judt: Postwar, S. 224.

203 Heinz-Hermann Krüger: Viel Lärm ums Nichts? Jugendliche „Existentialisten“ in den 50er Jahren. Spurensuche. In: Bucher, Deutscher Werkbund e. V. und Württembergischer Kunstverein Stuttgart (Hg.): Schock und Schöpfung. Jugendästhetik im 20. Jahrhundert. Darmstadt und Neuwied 1986, S. 263-268, hier S. 268.

204 Stephan Braese: Die „Exis“: Eine westdeutsche Jugendbewegung aus dem Geiste des Pariser Jazz. In: Braese und Vogel-Klein (Hg.): Zwischen Kahlschlag und Rive Gauche, S. 199213, hier S. 204. Als personifizierte Verbindung von Jazz und Existentialismus tritt hier Miles Davis auf, der wiederholt auf Sartre trifft, eine Liaison mit Juliette Gréco eingeht und überlegt, im vergleichsweise repressionsfreien Frankreich zu bleiben: „every night I would go out to the clubs with Sartre and Juliette and we would just sit in the outside cafes and drink wine and eat and talk. Juliette asked me to stay. Even Sartre said, ,Why don't you and Juliette get married?‘ But I didn't. I stayed a week or two, fell in love with Juliette and with Paris and then left.“ Miles Davis, Quincy Troupe: Miles. The Autobiography. London 2012 [1990], S. 117. 
,Existenzialisten“ bezeichneten und von der Welt so genannt wurden. “205 Verbindende Elemente sind durchaus vorhanden: Die europäische Jugend begrüßt den Jazz laut Alfred Andersch instinktiv „als Musik der Aktion“206, als Berührungspunkte nennt Colin W. Nettelbeck in seinem Aufsatz ,Jean-Paul Sartre, Simone de Beauvoir and the Paris jazz scene“ das In-Situation-Sein der Improvisation (die „dadurch gekennzeichnet ist, dass das, was der Sinn eines Elements ist, und damit das, was überhaupt ein Element ist, im Prozess der Improvisation ausgehandelt wird““207), die Offenheit, Freiheit, Spontaneität und kontinuierliche Erneuerung des Jazz-Spiels. Wie sich diese Aspekte in Sartres Werk eingeschrieben hätten, sei ein Paradebeispiel für kulturelle Anverwandlung:

In attempting to assess the relationship between jazz and the development of Sartre's philosophy the notions of ,impact' or ,influence' are perhaps less useful than the idea of appropriation. What goes in as jazz - that is as a cultural ,other full of emotional connotations - is not just absorbed into an existing intellectual tradition, but is deliberately appropriated as an agent of transformation, taking the form, ultimately, of writing that seeks to inflect and subvert ideologies and socio-political realities. ${ }^{208}$

In der österreichischen Aufnahme werden Jazz und Existentialismus teils bis zur Ununterscheidbarkeit miteinander verklammert: In Michael Köhlmeiers Roman Abendland heißt es über die aus Nordamerika eingetroffene musikalische Untermalung, „die verminderte Quint wurde als akustische Ikone jenes Lebensgefühls

gefeiert, das die Franzosen wenig später Existentialismus nannten“209. Aus musikwissenschaftlicher Sicht sekundiert Andreas Felber, der in seinem Buch über die Wiener Free Jazz-Szene die literarische Avantgarde hinzuzieht: „Die Neo-Traditional-Szene in Wien war zu Beginn, ähnlich wie in Paris, vom Geist des Existenzialismus behaucht und deshalb eng mit anderen Künstlerkreisen, u. a. der Wiener Gruppe, verknüpft.“210 Der in den fiktionalen Handlungsräumen immer wieder auftauchende „Jazzkeller“ - den Sartre und Beauvoir entgegen dem Klischee nicht allzu häufig frequentierten - ist bei Jelinek nicht nur im enge-

205 Améry: In die Welt geworfen, S. $195 \mathrm{f}$.

206 Alfred Andersch: Jugend am Schmelzpott einer Kultur. In: Andersch: Essayistische Schriften 1. (Gesammelte Werke in zehn Bänden, 8.) Zürich 2004, S. 279-292, hier S. 283. [Zuerst in: Aussprache 3 (1951), Nr. 1.]

207 Daniel Martin Feige: Philosophie des Jazz. Berlin 2014, S. 126.

208 Colin W. Nettelbeck: Jean-Paul Sartre, Simone de Beauvoir and the Paris Jazz Scene. In: Modern \& Contemporary France 9 (2001), Nr. 2, S. 171-181, hier S. 174 f. (Hervorhebung im Original).

209 Michael Köhlmeier: Abendland. München 2007, S. 26.

210 Andreas Felber: Die Wiener Free-Jazz-Avantgarde: Revolution im Hinterzimmer. Wien, Köln, Weimar 2005, S. 25. 
ren Sinne „Schauplatz“, sondern das eigentliche Biotop einer Jugend, die sich in der Natur nicht mehr ,in ihrem Element“ fühlt: „Ihre Lungen rasseln, keine Kondition [...]. Zuviel Alkohol, zuviel Zigaretten, prahlt Rainer und will über Camus debattieren“211. Zwar weicht der Umgang mit dem Existentialismus in Die Ausgesperrten insofern von der verbreiteten jugendlichen Rezeptionshaltung (,eher leidenschaftlich, weniger als rationale, methodische Auseinandersetzung mit einem philosophischen Konzept ${ }^{\text {‘212 }}$ ) ab, als er vielfach literarisch-philosophische Inhalte lakonisch aufgreift, doch berücksichtigt er auch den Lebensstil, jene von Franz Schuh beschriebene „Mode, ein eigentümliches Konglomerat aus Gesten und Meinungen mit dem Zweck, mittelständischen Existenzen die Dramatisierung ihres langweiligen Daseins zu ermöglichen.“213

Für den Schüler Rainer verfügt neben der Philosophie vor allem die Musik über ein hohes Distinktionspotenzial; über sie zu dozieren, hebt ihn von den anderen ab und ermöglicht ihm, im Bourdieuschen Sinne, die Breite und Universalität seiner Bildung zu demonstrieren (,[p]arler de la musique, c'est l'occasion par excellence de manifester l'étendue et l'universalité de sa culture“214). In musikalischen Präferenzen, die implizit der Reproduktion der eigenen sozialen Position dienten, spiegeln sich die Ungleichheiten zwischen Menschen Bourdieu zufolge auf beispiellose Weise: Nichts erlaube es, die eigene Klasse so sehr zu behaupten, wie der Musikgeschmack, nichts wiederum klassifiziere einen unweigerlicher (,[i]l n'y a rien qui, autant que les goûts en musique, permette d'affirmer sa ,classe،, rien aussi par quoi on soit aussi infailliblement classé“‘215). Die Annahme, dass Geschmack nicht Ausdruck von Individualität, sondern von Klasse sei, wird von Jelineks Hauptfiguren zugleich bestätigt und unterwandert. Die intellektuellen Höhenflüge der Figur Rainer beinhalten lange Vorträge „über die moderne coole Jazzmusik und deren Aufbau“ ${ }^{\text {216 }}$, andererseits erklärt er dem Arbeiter Hans den Rock'n'Roll. Hans, der sogenannte Halbstarke, will seinerseits aber auch ins Jazzlokal gehen. Die beiden Mitte der fünfziger Jahre vorherrschenden, gemeinhin den BürgerInnen und ArbeiterInnen zugeord-

211 Jelinek: Die Ausgesperrten, S. 107, 95.

212 Andreas Weber: Stimmen der Gegenwart, eine Anthologie - Nachkriegsösterreich aus der Sicht junger Autor(inn)en. Wien: Universität Wien, Dipl.-Arbeit 1990, S. 15.

213 Franz Schuh: Lest Sartre! In: Profil, 21.04.1980.

214 Pierre Bourdieu: L’Origine et l'évolution des espèces de mélomanes. [Interview mit Cyril Huvé.] In: Bourdieu: Questions de sociologie. Paris 2002 [1984], S. 155-160, hier S. 155. [Zuerst in: Le Monde de la musique, Nr. 6, Dezember 1978.]

215 Bourdieu: L'Origine et l'évolution des espèces de mélomanes, S. 155. Cf. Pierre Bourdieu: La Distinction. Critique sociale du jugement. Paris 1979, S. 17.

216 Jelinek: Die Ausgesperrten, S. 200; cf. S. 176. 
neten Gruppierungen, „Jazzer und Rock 'n' Roller“6217, trennt Die Ausgesperrten nicht klar voneinander. Es veranschaulicht vielmehr, wie der Jazz, als „Sprachrohr für Subversion aller Art“218, mit dem noch schockierenderen Rock'n'Roll „eine enge Liaison“ ${ }^{219}$ eingeht.

In diesem Sinne reklamierbar macht den Jazz die Tatsache, dass er „trotz

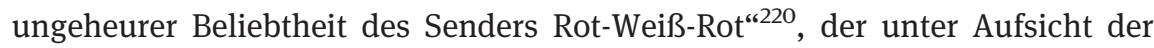
amerikanischen Besatzungsbehörde steht, eine laut Rathkolb von weiten Gesellschaftsschichten prinzipiell abgelehnte schwarze Musik bleibt. Während er sich für die Jugendlichen dadurch mit subkulturellem Kapital auflädt, wird er für die Elterngeneration zum Synonym für mangelnden Lebensernst und Verantwortungslosigkeit: „Er will nur die neuesten Jazzplatten hören und ist weder genügsam noch bescheiden“, fasst in Jelineks Roman Rainers Tante das Verhalten ihres Neffen zusammen. „Oft sind diese jungen Leute, die nur tanzen und Jazzmusik hören wollen, zu unreif, um mit einer Freiheit auch umzugehen, deswegen nimmt man sie ihnen wieder weg“221, räsoniert Vater Witkowski. Es treibt den Arbeiter Hans ebenso wie die Witkowski-Zwillinge der Wunsch an, aus der elterlichen Klasse auszubrechen, was ein wesentliches Element des subkulturellen Habitus ist, doch beruht subkulturelle Distinktion laut Sarah Thornton gerade auf einer „fantasy of classlessness“222, die in Jelineks Handlung nur bedingt gegeben ist; ebenso in der Realität: Die ExistentialistInnen, überwiegend aus studentisch-künstlerischem Milieu in den Städten, grenzen sich im Allgemeinen „bewusst von arbeiterjugendlichen Ausdrucks- und Verhaltensformen ab, wussten jedoch antiproletarische Grundhaltungen mit konventionslos-antibürgerlichen Attitüden zu einer spezifischen Form jugendlicher Gegenkultur und Zivilisationskritik zu verbinden.“"223 Der sich dezidiert antibürgerlich gerierende Kleinbürger Rainer verachtet Hans, den „von Karl Marx zu Elvis degenerierte[n] Arbeiter“224 ${ }^{\star 22}$ der sich seinem illegitimen Unterklassen-Ge-

217 Deisl: Im Puls der Nacht, S. 147.

218 Deisl: Im Puls der Nacht, S. 115.

219 Zinnecker: Jugendkultur 1940-1985, S. 161.

220 Rathkolb: Die Entwicklung der US-Besatzungskulturpolitik, S. 38.

221 Jelinek: Die Ausgesperrten, S. 161, 35.

222 Sarah Thornton: The Social Logic of Subcultural Capital [1995]. In: Thornton und Gelder (Hg.): The Subcultures Reader. London und New York 1997, S. 200-209, hier S. 204. Bei einer Subkultur handelt es sich nach Schwendter um einen Gesellschaftsteil, „der sich in seinen Institutionen, Bräuchen, Werkzeugen, Normen, Wertordnungssystemen, Präferenzen, Bedürfnissen usw. in einem wesentlichen Ausmaß von den herrschenden Institutionen etc. der jeweiligen Gesamtgesellschaft unterscheidet.“ Rolf Schwendter: Theorie der Subkultur. Köln 1973, S. 11.

223 Hüser: Amerikanisches in Deutschland und Frankreich, S. 299.

224 Sichrovsky: Die Ausgesperrten, S. 10. 
schmack, dem Rock'n'Roll, widmen und sich aus Rainers Fachgebiet, dem Jazz, heraushalten soll. Hier greift ein Hauptmechanismus des subkulturellen Kapitals, von dem Thornton in Anlehnung an Bourdieus kulturelles Kapital spricht:

Subcultural capital confers status on its owner in the eyes of the relevant beholder. It affects the standing of the young in many ways like its adult equivalent. [...] Just as cultural capital is personified in ,good' manners and urbane conversation, so subcultural capital is embodied in the form of being, in the know ${ }^{2225}$.

Nach diesem Muster betont Rainer, Camus’ Der Fremde nur gemeinsam mit der von ihm verehrten Sophie „und sonst niemandem“ zu lesen, auch will er „ihr alleine jetzt einige Ideen für die Interpretation der Pest von Camus anvertrauen, weil sie das als nächstes zusammen lesen werden. Sie darf es nicht weitersagen.“226 Während sich die Figur Sophie dieser Gunst kaum als würdig erweist, fühlen sich andere EmpfängerInnen eines solchen Insider-Wissens aufgewertet, etwa das Ich in Brigitte Schwaigers Erfolgsroman Wie kommt das Salz ins Meer (1977):

Ich wollte wissen, was er meinte, als er einmal sagte: Du bist für mich wahrscheinlich, was für Caligula der Mond ist. Karl hat Sartre und Camus gelesen. Ich habe alle Briefe aufbewahrt, die er mir geschrieben hat. Ich war so stolz, daß einer mir Briefe schrieb, die so gescheit waren, daß ich sie nicht verstand. ${ }^{227}$

Johannes Mario Simmels Roman Liebe ist nur ein Wort geht, den Pygmalion-Mythos variierend, noch einen Schritt weiter, indem er den Helden ein Kind mit existentialistischer Lektüre zu seinem ,Geschöpf‘ formen lässt:

Darum unterhalte ich mich mit Chichita über Jaspers und Sartre, Oppenheimer, den ,Verrat im zwanzigsten Jahrhundert', die Kollektivschuld, Brecht, und so weiter.“ „Davon versteht sie doch noch kein Wort, Noah!“ „Das sagen Sie nicht, Herr Doktor! Ich habe ihr Camus gegeben. Und Malraux. Und Koestler. Sie haben recht, vieles versteht sie nicht, auch wenn sie behauptet, alles zu verstehen. Aber eine Menge bleibt doch hängen, eine Menge versteht sie - unbewußt, unterbewußt. Es wird ihr nie bewußt werden, aber sie wird einmal so handeln, wie zum Beispiel Camus gedacht hat. Ist das schlecht?228

225 Thornton: The Social Logic of Subcultural Capital, $202 \mathrm{f}$.

226 Jelinek: Die Ausgesperrten, S. 196, 254.

227 Brigitte Schwaiger: Wie kommt das Salz ins Meer. Reinbek 1979, S. 52. In Schwaigers Spätwerk Fallen lassen (Wien 2006, S. 22) tauchen erneut ExistentialistInnen auf, nun als beliebter Bibliotheksbestand der psychiatrischen Einrichtung Baumgartner Höhe (,Steinhof'): „Wer ein Buch bringt, um es dann der Bibliothek einzugliedern, Camus etwa, Jandl, Sartre, der findet das Buch schon nach zehn Minuten nicht mehr. Patienten nehmen es mit bei der Entlassung oder hinterlassen das Exemplar mit nur noch halber Seitenanzahl.“

228 Johannes Mario Simmel: Liebe ist nur ein Wort. München, Zürich 1963, S. 455. 
Anders als in diesen Beispielen von Schwaiger und Simmel geht das ,in the know'-Sein häufig mit einer Abwertung der Uneingeweihten einher: Jelineks Witkowski-Geschwister „begiften einen Muskelprotz, der nicht weiß, wer Sartre und Camus sind und wo diese wohnen (Frankreich)“229. Dass es dabei ausreicht, auch unverstandenes existentialistisches Wissen für sich zu beanspruchen, veranschaulicht ein Gedicht von Peter Turrini:

\author{
Meine Einsamkeit \\ und meine Lesewut \\ waren grenzenlos. \\ Ich las alles \\ von Dostojewski \\ bis zu den \\ Existentialisten \\ und verstand nichts. \\ Einen Schulfreund \\ der mir seine Liebeserfahrungen \\ im Detail schilderte \\ versuchte ich mit der Frage \\ ob er überhaupt \\ Camus und Sartre \\ gelesen habe \\ fertigzumachen. ${ }^{230}$
}

Die erwähnte außenseiterische Einsamkeit wirkt dabei als wesentlicher Antrieb:

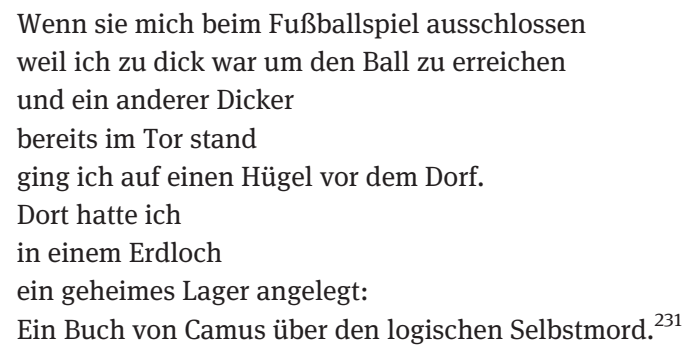

Trost findet auch der junge Josef Winkler in der existentialistischen Philosophie, besonders in Aussagen, die der Enge seiner Kindheit im ländlichen Kärnten, aus der sein eigenes literarisches Werk entstehen soll, Ausdruck verleihen. So heißt es in Winklers Zöglingsheft des Jean Genet: „,Man ,überwindet“ den

229 Jelinek: Die Ausgesperrten, S. 154.

230 Peter Turrini: Ein paar Schritte zurück. Hg. von Silke Hassler. Frankfurt am Main 2002 [1980], S. 70.

231 Turrini: Ein paar Schritte zurück, S. 48. 
Katholizismus nicht: wenn es einem gelingt, sich von ihm loszureißen, so bleibt man halb tot und für immer gezeichnet zurück', so Jean-Paul Sartre.“232 Es ist die Beschäftigung mit Jean Genet, die Winkler zu Sartres Studie Saint Genet. Comédien et Martyr (1952, auf Deutsch zuerst 1982) führt, ${ }^{233}$ aus der er auch in Muttersprache, dem letzten Teil seiner Trilogie Das wilde Kärnten, zitiert. Die Überlegungen Sartres scheinen auf im Rahmen einer empfundenen Unfreiheit des Ichs gegenüber seinen Eltern, die „das Wort Homosexualität nie gehört“ haben und daher nie wussten, wer er sei:

Man wird nicht als Homosexueller geboren, sagt Sartre, aber man kann, je nach den Ereignissen und den Reaktionen darauf, ein Homosexueller werden. Alles hängt davon ab, wie man auf das antwortet, was einem von anderen angetan wird. Homosexualität, so Sartre, ist etwas[,] das von einem Kind in einem entscheidenden Moment, einem Moment des Erstickens, entdeckt oder erfunden wird. ${ }^{234}$

Winkler lässt seinen Helden damit eine Passage aus Sartres Saint Genet unbewertet paraphrasieren, in der es heißt:

\begin{abstract}
Man ist nicht homosexuell oder normal geboren: jeder wird das eine oder das andere, je nach den Vorfällen seiner Geschichte und seiner eigenen Reaktion auf diese Vorfälle. Ich halte daran fest, daß die Inversion weder das Ergebnis einer pränatalen Wahl noch das einer endokrinen Mißbildung ist, noch gar das passive und bestimmte Resultat von Komplexen: es ist ein Ausweg, den ein Kind im Moment des Erstickens entdeckt. ${ }^{235}$
\end{abstract}

(On ne naît pas homosexuel ou normal: chacun devient l'un ou l'autre selon les accidents de son histoire et sa propre réaction à ces accidents. Je tiens que l'inversion n'est pas l'effet d'un choix prénatal, ni d'une malformation endocrinienne ni même le résultat passif et déterminé de complexes: c'est une issue qu'un enfant découvre au moment d'étouffer.) ${ }^{236}$

Dieselbe Passage findet sich, neben zahlreichen weiteren Sätzen aus Sartres Saint Genet, auch in Winklers Das Zöglingsheft des Jean Genet. ${ }^{237}$ Sartre erscheint

232 Josef Winkler: Das Zöglingsheft des Jean Genet. Frankfurt am Main 2010 [1992], S. 94.

233 Cf. Winkler: Winnetou, Abel und ich, S. 54.

234 Josef Winkler: Muttersprache. In: Winkler: Das wilde Kärnten. Menschenkind. Der Ackermann aus Kärnten. Muttersprache. Frankfurt am Main 1995 [1979], S. 473-849, hier S. 800.

235 Jean-Paul Sartre: Saint Genet, Komödiant und Märtyrer. Deutsch von Ursula Dörrenbächer. (Gesammelte Werke, Schriften zur Literatur.) Reinbek 1986, S. $128 \mathrm{f}$.

236 Jean-Paul Sartre: Saint Genet. Comédien et Martyr. Paris 1952, S. 94. Cf. zu Sartres noch früherer Theoretisierung der Homosexualität im Lichte der mauvaise foi: L'Être et le Néant, S. 98-102.

237 Cf. Winkler: Das Zöglingsheft des Jean Genet, S. 18, 36, 56, 70-72, 74f., 77, 89, 91, 94, 96. 
hier als Gewährsmann für die eigenen Gedanken, die in den entscheidenden Jahren vom Existentialismus geprägt wurden, so Winkler in Winnetou, Abel und ich:

Keines meiner Familienmitglieder wagte es, sich über meinen Lärm mit der Schreibmaschine aufzuregen. Anschlag für Anschlag, schritt- und buchstabenweise nahm ich Abschied von den Eltern und Abschied von der Schule. Wohl fuhr ich morgens mit dem Omnibus nach Villach, ging aber nicht mehr in die Handelsschule, sondern in die Konditorei Kleinsasser auf dem Villacher Kirchplatz, unweit der drei Kinos, dem Apollokino, dem Stadtkino und dem Elitekino, las von Camus den Roman ,Der Fall', von Sartre ,Das Spiel ist aus', von Antoine de Saint-Exupéry ,Dem Leben einen Sinn geben', von William Faulkner ,Licht im August ${ }^{.238}$.

Neben den Romanen, in denen der Existentialismus Handlungsbestandteil ist, sind es oft (fiktionalisierte) Jugenderinnerungen, in die er Eingang findet. Unter den in den siebziger und achtziger Jahren aktiven AutorInnen sind viele von der Strömung insofern berührt, als ihre Kindheit und Jugend in die Phase fällt, in der Sartre und Camus wesentliche Orientierungsfiguren waren, was beispielsweise auf Gerhard Roth ${ }^{239}$ ebenso zutrifft wie auf Thomas Bernhard, in dessen letztveröffentlichtem Roman Auslöschung (1986) der Schriftsteller Sartre „zu den allergrößten“ ${ }^{240}$ gezählt wird. Oft scheinen Sartres und Camus’ Namen ohne Lob, Kritik und Kommentar in Aufzählungen von Lektüreerfahrungen oder -präferenzen auf. Ein anschauliches Beispiel für solche Art name-dropping liefert Johannes Mario Simmel:

Ich ging zu der Bücherwand und betrachtete die Titel und Autoren der Bücher. Camus. Sartre. Hemingway. Greene. Mailer. Giono. Malraux. Priestley. Huxley. Bertrand Russell. Mary McCarthy. Silone. Pavese. Irwin Shaw. Irving Wallace ... lauter Autoren, die auch ich gerne hatte und besaß, nicht in Französisch natürlich, sondern deutsch. ${ }^{241}$

238 Winkler: Winnetou, Abel und ich, S. 29.

239 Grill-Fuchs' überwiegend typologischer Vergleich in „Hölle oder Himmel?“ Der Einfluss von Albert Camus' und Jean-Paul Sartres Existentialismus auf das Romanwerk von Gerhard Roth kommt zu dem Ergebnis, dass „sich der existentialistische Einfluss von Camus und Sartre praktisch durch das gesamte Prosawerk von Roth als roter Faden hindurchziehen lässt“ (S. 20). Cf. S. 24-28: Die literarische Sozialisation Roths beinhaltet zu Beginn der 1960er Jahre auch intensive Begegnungen mit den im existentialistischen Kontext immer wieder als einflussreich genannten Autoren Kafka, Faulkner, Hemingway und Dostojewski.

240 Thomas Bernhard: Auslöschung. Ein Zerfall. Hg. von Hans Höller. (Werke, 9.) Frankfurt am Main 2018, S. 110; cf. S. 369: Bernhards Held und seine FreundInnen (darunter eine Ingeborg Bachmann nachempfundene Figur) schätzen (in einer Traumszene) besonders Sartres Autobiographie Les Mots, „die wir, alle drei zur gleichen Zeit und tatsächlich alle drei von dieser Gleichzeitigkeit nichts wissend, gelesen hatten. Bis in die tiefe Nacht hinein hatten wir damals Die Wörter besprochen in einer Ausführlichkeit, die wir noch keinem Buch vorher zuteil werden haben lassen.“

241 Johannes Mario Simmel: Die Antwort kennt nur der Wind. München, Zürich 1973, S. 143. 
Während hier keine sonderlich einheitliche Ahnengalerie entsteht, spezialisiert sich vor allem Gstreins Roman Eine Ahnung vom Anfang auf die in einem Nahverhältnis stehenden Bücher der in jeder Schulklasse sitzenden „SteppenwolfLeser und die Siddhartha-Leser, die auf der Suche nach sich selbst für eine Weile keinen Boden mehr unter den Füßen hatten“242. Als ein Favorit tritt dabei Miroslav Krležas Ohne mich (Na rubu pameti, 1938) hervor, dessen subversives Potential Gstreins Held hoch einschätzt: „Sobald jemand es nur mit ein bisschen Verstand liest, wird er kaum mehr einen Chef über sich akzeptieren und überhaupt ein Problem mit den Lügen haben, die unsere Geschäftswelt zusammenhalten.“243 Trotz der stark von Sartres Prosa abweichenden erzählerischen Opulenz weist dieser Roman des schon ,Balkan-Sartre“ geheißenen kroatischen Autors thematisch viele Parallelen zu dem im selben Jahr veröffentlichten La Nausée (1938) auf. Gerade in der Auflehnung gegen den Typus des homme de droit, den sich auf gegebene Rechte und Pflichten stützenden Menschen, der sich „,in Würden und Missionen, in Berufe und Rangklassen“ („dostojanstvom i pozivima, zvanjima i činovima“) hüllt, ähnelt Krležas Ich Sartres Protagonisten Roquentin; desgleichen im Leitgefühl des Ekels: Auch ihm wird das Leben „abstoßend bis zu jenem Grad des Abscheus, mit dem das menschliche Gehirn auf die Sinnlosigkeit der Existenz an sich zu reagieren pflegt، ${ }^{244}$ (,do onog bezidejnog, upravo bespredmetnog stupnja gađenja, kakvim ljudski mozak reagira na besmislenost postojanja uopće kao takvog“ ${ }^{245}$. Nichtsdestoweniger wird Krležas Werk selten in den intertextuellen Raum (proto)existentialistischer Literatur gerückt. In diesem findet sich eher Prosa von VorläuferInnen und VertreterInnen wie Alberto Moravia, Juan Carlos Onetti, dem frühen André Malraux, Ernesto Sabato, Hans Erich Nossack, Richard Wright, Paul Bowles und Walker Percy, die trotz ihrer Heterogenität eine Reihe von Übereinstimmungen in Thematik und Motivik eint. ${ }^{246}$ Percys

242 Gstrein: Eine Ahnung vom Anfang, S. 208.

243 Gstrein: Eine Ahnung vom Anfang, S. 259.

244 Miroslav Krleža: Ohne mich. Deutsch von Ina Jun-Broda. Reinbek 1966, S. 6, 28 f.

245 Miroslav Krleža: Na rubu pameti. Zagreb 1960, S. 11.

246 Cf. etwa Richard E. Baker: The Dynamics of the Absurd in the Existentialist Novel. (American University Studies XIX/31.) New York et al. 1993. Wie dehnbar das Subgenre der existentialistischen Literatur ist, zeigt sich an der nicht seltenen Zuordnung von SchriftstellerInnen verschiedener Epochen, die sich existentiellen Topoi angenommen haben, von Ibsen über Hofmannsthal, Rilke und Gide bis zu Beckett und Anouilh. Cf. Franz Josef Deiters: Literatur. In: Thurnherr und Hügli (Hg.): Lexikon Existenzialismus und Existenzphilosophie, S. 158-160. Für Untersuchungen des Existentialismus als literarische Strömung cf. auch Catharine Savage Brosman: Existential Fiction. (Literary Topics 8.) Farmington Hills/MI 2000; und Hans van Stralen: Choices and Conflict. Essays on Literature and Existentialism. Brüssel 2005. Cf. weiters 
Der Kinogeher (The Moviegoer, 1961) und Bowles’ Himmel über der Wüste (The Sheltering Sky, 1949) etwa werden in Gstreins Eine Ahnung vom Anfang durch die Nennung ihrer Titel zu Chiffren für existentielle Erfahrungen, ebenso Hemingways Kurzgeschichte „Schnee auf dem Kilimandscharo“ (,The Snows of Kilimanjaro“, 1936), welche zusammen mit der Sammlung Der Sieger geht leer aus (Winner Take Nothing, 1933) auch Josef Winkler als wegweisende Jugendlektüre nennt. Stellvertretend für die vielen Hemingway-Begeisterten unter den vom Existentialismus geprägten Schreibenden nach 1945 sei Fritz Habeck erwähnt, der zwischen 1950 und 1952 „zehn sehr persönliche Briefe“‘247 mit dem amerikanischen Vorbild austauscht.

Dieser vorangegangenen Literatur, die im Nachkriegsösterreich größtenteils zeitgleich mit dem Existentialismus rezipiert wird, messen Sartre und Beauvoir in ihrer eigenen schriftstellerischen Entwicklung einige Bedeutung zu. Vor dem Krieg sei es das Verdienst von William Faulkner und John Dos Passos gewesen, ihnen neue Schreibweisen und über ihre Literatur die USA gezeigt und als Korrektiv gegen verzerrte Wahrnehmungen („des prismes déformants“248) gewirkt zu haben. Das Vertrautmachen mit einer anderen Kultur über fiktionale Darstellungen kann jedoch durchaus zu unzutreffenden Ergebnissen führen, warnt Leslie Fiedler am Beispiel Sartre:

I should have realized (and in a way did) that Europeans have an odd habit of reading our most poetic books as anthropological documents. I had seen in New York, for instance, several years ago, Sartre's melodrama, The Respectful Prostitute, and knew what happened when one took Faulkner's parochial symbols of universal human guilt and endurance as a factual account of life in the specific American South. But such disingenuous misunderstandings seemed to me then peripheral and comic. ${ }^{249}$

In der Wiener Redaktion des von der französischen Besatzung herausgegebenen Bulletins Kulturelles, in der man Distanz zu amerikanischen Kulturgütern

die Sammelbände von Blasberg und Deiters (Hg.): Denken / Schreiben (in) der Krise - Existentialismus und Literatur; sowie von Helene Harth und Volker Roloff (Hg.): Literarische Diskurse des Existentialismus. (Romanica et Comparatistica 5.) Tübingen 1986.

247 Andreas Weber: Über die Kluft zwischen Generationen. Eine Vorgeschichte statt einer Einleitung. In: Weber (Hg.): Dear Fritz. Aufsätze und Gespräche über Fritz Habeck. St. Pölten 1998, S. 9-19, hier S. 15.

248 Beauvoir: La Force de l'âge, S. 160.

249 Leslie A. Fiedler: The „Good American“ (1954). In: Fiedler: An End to Innocence. Essays on Culture and Politics. New York 1972, S. 109-114, hier S. 110. 
hält, ist die hohe Meinung von Sartres als authentisch amerikanisch empfundenem Südstaaten-Drama hingegen spürbar:

Jean Paul Sartre brachte bei seiner Rückkehr aus den U.S. A. sein Stück „La Putain respectueuse“ (Die ehrfurchtsvolle Hure) auf die französische Bühne. Es hätte ebensogut von einem Autor „von drüben“ verfasst sein können, denn es behandelt das Vorurteil der Rasse sowie das Pharisäertum, Themen, die immer wieder von Richard Wright und Erskin Caldwell ausgewertet wurden. ${ }^{250}$

La Putain respectueuse hat seine Wirkung auf das Denken und Schreiben österreichischer AutorInnen nicht verfehlt, etwa auf Milo Dor, der in seiner Autobiographie berichtet, dass eine von ihm besuchte Pariser Aufführung sein Verhalten den Vereinigten Staaten gegenüber „,auf lange Zeit, letztlich bis heute“251 , beeinflusst hat.

Auch in Österreich selbst beginnt man à l'américaine zu schreiben, moniert Thomas Bernhard, der Anfang der fünfziger Jahre als Kulturredakteur in der amerikanischen Besatzungszone Salzburg arbeitet: „Damals [...] haben die Leute ja, auch die bekannten, immer Romane geschrieben, die in Oklahoma gespielt haben oder in New York. Kein Mensch ist auf die Idee gekommen, daß er das beschreibt, wo er lebt und wo er aufgewachsen ist und wovon er wirklich was weiß.“252 Verwundern tut ihn das nicht, in Anbetracht des Rezeptionsangebots (134 Millionen englischsprachige Bücher werden allein in den Marshallplan-Jahren 1948 bis 1953 in Umlauf gebracht): ${ }^{253}$ Die Schaufenster der

250 o. V.: Amerika in der modernen französischen Literatur. In: Kulturelles, 12.01.1948. Wer erfolgreich diesen Eindruck, ,von drüben` zu sein, erweckt, ist Sartres und Beauvoirs Bekannter Vian, der vor allem in seiner Funktion als Les Temps modernes-Redakteur und Musikkritiker als Vermittler amerikanischer Kultur auftritt: „America was one of Vian’s most enduring fascinations, born of a love of jazz and matured by the postwar Continental vogue for all things transatlantic.“ Halpern: Prince of Saint-Germain. In: The New Yorker, 25.12.2006. Mitte der vierziger Jahre schreibt Vian als „Imaginary American“ (Fiedler: Cross the Border - Close the Gap, S. 277) unter dem Pseudonym Vernon Sullivan vier Pastiche-Kriminalromane amerikanischer Art, als deren Übersetzer er sich ausgibt, darunter den Aufsehen erregenden Bestseller J'irai cracher sur vos tombes. Selbst Beauvoir bemerkt erst während ihres USA-Aufenthalts 1947, dass es Sullivan nicht gibt. Cf. Simone de Beauvoir: Lettres à Sartre, 1940-1963. Paris 1990, S. 308.

251 Milo Dor: Auf dem falschen Dampfer. Fragmente einer Autobiographie. Wien, Darmstadt 1988, S. 204.

252 Thomas Bernhard. In: Kurt Hofmann: Aus Gesprächen mit Thomas Bernhard. Mit Photographien von Sepp Dreissinger und Emil Fabjan und einer Vorbemerkung des Verlags. Wien 1988, S. 26.

253 Von großer Bedeutung als Vermittlungsorte amerikanischer Literatur sind zudem die Amerika-Häuser, wie Judt betont: „[A] significant percentage of the population of Vienna and 
Buchhandlungen des Jahres 1953 „könnten ebensogut in Chicago oder Indianapolis sein“ ${ }^{254}$. Angesichts dieser Dominanz stellt sich ein gewisser Überdruss ein, weil sie mit der Vernachlässigung österreichischer SchriftstellerInnen korreliere, deren Kunst im Wesentlichen darin bestehe, „sich von einem Tag zum andern am Leben zu erhalten“255. Bernhard selbst zeigt in den Nachkriegsjahren an sich reges Interesse an LiteratInnen wie O’Neill, Hemingway, Thurber und Wolfe, die seinen Landsleuten, „den immer noch so sehr Traditionsgebundenen, den in mancher Hinsicht Auswegsuchenden“256, viel zu sagen hätten.

Vor allem die Authentizität und Dramatik, mit der amerikanische AutorInnen das Leben beschrieben, lassen ihren Einfluss auf die französische Literatur seit der Zwischenkriegszeit für Beauvoir sehr profitabel erscheinen. ${ }^{257}$ Sie und Sartre unterstreichen die Wichtigkeit Hemingways, Dos Passos', Steinbecks und Faulkners als engagierte amerikanische Literatur („la littérature ,engagée“ américaine“ ${ }^{\text {258 }}$ ):

Was die Amerikaner angeht, so haben sie uns weder durch ihre Grausamkeit noch durch ihren Pessimismus berührt: wir haben in ihnen Menschen erkannt, die in einem zu großen Kontinent ebenso überwältigt, verloren waren wie wir in der Geschichte und die ohne Traditionen mit den erstbesten Mitteln ihre Benommenheit und ihre Verlassenheit mitten in unverständlichen Ereignissen wiederzugeben versuchten. Der Erfolg von Faulkner, Hemingway und Dos Passos ist nicht das Ergebnis des Snobismus gewesen oder zumindest nicht zuerst: es war der Abwehrreflex einer Literatur, die sich bedroht fühlte, weil ihre Techniken und ihre Mythen ihr nicht mehr ermöglichen würden, der historischen Situation ins Gesicht zu sehen, und sich daher fremde Methoden aufpfropfte, um in neuen Konstellationen ihre Funktion erfüllen zu können. ${ }^{259}$

Salzburg [...] visited their local America House to borrow books and read the papers.“ Judt: Postwar, S. 224.

254 Thomas Bernhard: Wo sind die österreichischen Dichter? In: Bernhard: Werke, Bd. 22/1, S. 168-170, hier S. 170. [Zuerst in: Demokratisches Volksblatt, 08.06.1953.]

255 Thomas Bernhard [Th. B.]: Junge Dichter in Österreich. In: Bernhard: Werke, Bd. 22/1, S. 13-15, hier S. 13. [Zuerst in: Demokratisches Volksblatt, 21.01.1952.]

256 Thomas Bernhard [Th. B.]: Helene Thimig las amerikanische Dichter. In: Bernhard: Werke, Bd. 22/1, S. 93-94, hier S. 93. [Zuerst in: Demokratisches Volksblatt, 02.12.1952.]

257 Cf. Simone de Beauvoir: An American Renaissance in France. In: The New York Times, 22.06.1947. Cf. Jean-Paul Sartre: American Novelists in French Eyes. In: The Atlantic Monthly 178 (1946), Nr. 2, S. 114, 117.

258 Beauvoir: La Force des choses, Bd. 1, S. 117. Dieses Interesse schlägt sich 1946 in der ersten USA-Sonderausgabe der Temps modernes (August-September) nieder, im November 1946 folgt die Zeitschrift Esprit mit einem „L’homme américain“ (,Der amerikanische Mensch`) betitelten Sonderheft.

259 Sartre: Was ist Literatur?, S. 175. 
(Quant aux Américains ce n'est pas par leur cruauté ni par leur pessimisme qu'ils nous ont touchés: nous avons reconnu en eux des hommes débordés, perdus dans un continent trop grand comme nous l'étions dans l'Histoire et qui tentaient, sans traditions, avec les moyens du bord, de rendre leur stupeur et leur délaissement au milieu d'événements incompréhensibles. Le succès de Faulkner, d'Hemingway, de Dos Passos n'a pas été l'effet du snobisme, ou du moins, pas d'abord: ce fut le réflexe de défense d'une littérature qui, se sentant menacée parce que ses techniques et ses mythes n'allaient plus lui permettre de faire face à la situation historique, se greffa des méthodes étrangères pour pouvoir remplir sa fonction dans des conjectures nouvelles. $)^{260}$

Neuartige Methoden, um dieser Erfahrung des Unverständlichen Ausdruck zu verleihen, finden Sartre, Beauvoir und Camus nicht nur in der amerikanischen Hoch- und Populärkultur, deren Einflüsse sie sich anverwandeln und weitertragen, sondern auch in der Prosa Franz Kafkas. In den zwanziger und dreißiger Jahren als Teil der deutschsprachigen Tradition in Frankreich rezipiert, realisiert sich in weiterer Folge ein spezieller Fall transkultureller Verschmelzung (métissage): die Verzahnung eines sich neu bildenden jungen österreichischen Kanons, dessen Spitze Kafka darstellt, mit der zeitgleichen Aufnahme des von Kafka bereits inspirierten Existentialismus.

260 Sartre: Qu'est-ce que la littérature?, S. $227 \mathrm{f}$. 